The Inter national research Institute for Climate prediction Linking Science to society

IRI Tech n ical REport No. 01-04

\title{
Sensitivity of Seasonal Climate Forecasts to Persisted SST Anomalies
}

December 2001
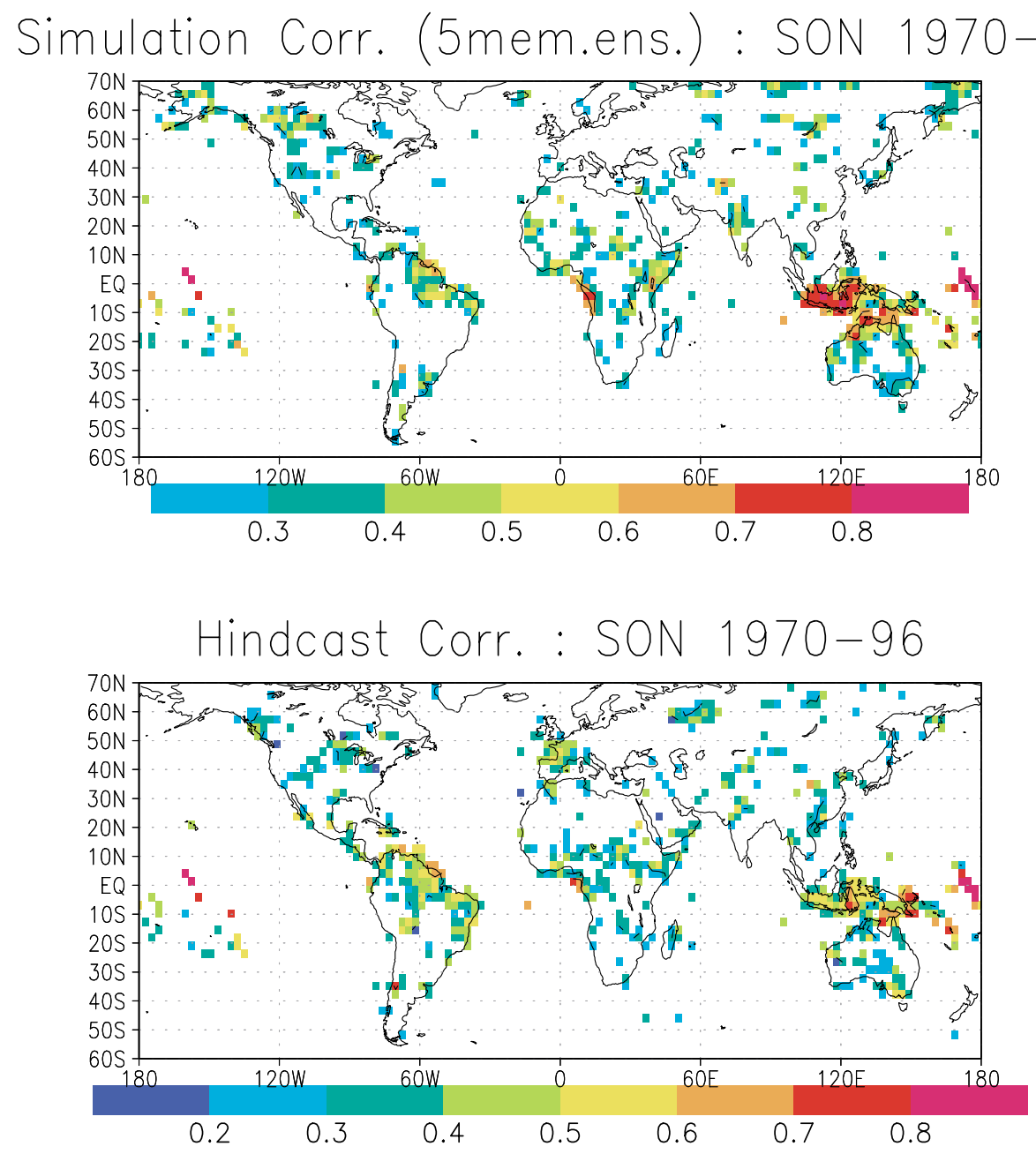

Columbia earth institute columbia university in the city of new york 


\title{
Sensitivity of Seasonal Climate Forecasts to Persisted SST Anomalies
}

\author{
L. GODDARD $(†)$ S. J. MASON
}

International Research Institute for Climate Prediction, Lamont Doherty Earth Observatory, Columbia University, Route 9W, Palisades, NY

Climate Research Division, Scripps Institution of Oceanography, University of California San Diego, La Jolla, CA 92093-0230

E-mail: goddard@iri.columbia.edu

Tel: 8456804430

Fax: 8456804865

E-mail: smason@ucsd.edu

Tel: 8588222574

Fax: 8585348561

December 18, 2001 


\begin{abstract}
Most estimates of the skill of atmospheric general circulation models (AGCMs) for forecasting seasonal climate anomalies have been based on simulations with actual observed sea surface temperatures (SSTs) as lower boundary forcing. Similarly estimates of the climatological response characteristics of AGCMs used for seasonal-to-interannual climate prediction frequently rest on historical simulations using "perfect" SST forecasts. This paper examines the errors and biases introduced into the seasonal climate response of an AGCM forced with persisted SST anomalies, which are generally considered to constitute a good prediction of SST in the first 3-month season. However, the added uncertainty introduced by the predicted SST anomalies weakens, and in some cases nullifies, the skill of atmospheric predictions that is possible given perfect SST forcing. The use of persisted SST anomalies also leads to changes in local signal-to-noise characteristics. Thus, it is argued that seasonal-to-interannual forecasts using AGCMs should be interpreted relative to historical runs that were subject to the same strategy of boundary forcing used in the current forecast in order to properly account for errors and biases introduced by the particular SST prediction strategy. Two case studies are examined to illustrate how the sensitivity of the climate response to predicted SSTs may be used as a diagnostic to suggest improvements to the predicted SSTs.
\end{abstract}




\section{Introduction}

The predictability of seasonal climate anomalies results primarily from the influence of slowly evolving boundary conditions, and most notably sea-surface temperatures (SSTs), on the atmospheric circulation (Palmer and Anderson 1994; Goddard et al. 2001). Because of feedbacks between the ocean and the atmosphere, the coupled system may be predictable in some regions of the tropics a year or more in advance (Barnston et al. 1994; Latif et al. 1994, 1998; Neelin et al. 1998), although operational forecast skill is more realistically limited to lead-times of a few months (Barnston et al. 1999a; Landsea and Knaff 2000; Mason and Mimmack 2002). At shorter lead-times of about three months or less, but beyond the period in which forecast skill from initial conditions remains discernible (Brankovic et al. 1990, 1994; Brankovic and Palmer 2000), changes in the boundary conditions are sufficiently slow compared to the predictability limit for the atmosphere alone that seasonal climate forecasting is possible even in the absence of detailed projections of the evolution of the boundary layer. Throughout much of the tropical oceans, and in some areas of the mid-latitudes, the autocorrelation of monthly SST anomalies (SSTAs) remains geater than 0.5 at lags of six months or more (Fig. 1). Because the ocean is more slowly evolving than the atmosphere, the assumption that current anomalous conditions will persist over the next season provides an accurate forecast of oceanic conditions for the next few months in many regions. Forecasts for persistent SST anomalies out to 3 months lead cannot be outscored by even the most sophisticated forecast models (Latif et al. 1994, 1998; Stockdale et al. 1998; Goddard et al. 2001).

Although boundary conditions provide predictability of the atmosphere at seasonal timescales, the inherent variability of the atmosphere requires seasonal climate forecasts be expressed probabilistically (e.g. Barnston et al. 1999b; Mason et al. 1999; Goddard et al. 2001). Forecast ensembles are a standard method of estimating the uncertainty in seasonal climate by sampling the distribution of possible climate outcomes. However, ensembles may not provide reliable estimates of forecast uncertainty due to model errors; in other words, the chaotic evolution of the atmosphere is not the only source of forecast uncertainty. Systematic model errors can be corrected statistically (Ward and Navarra 1998; Feddersen et al. 1999; Mason 
et al. 1999), but these errors are likely to be conditional upon the state of the boundary forcing (Mo and Wang 1995), which, in turn, is subject to its own forecast uncertainty. Most estimates of the forecast skill and structures of systematic forecast errors of AGCMs are based on model simulations using observed SSTs (e.g. Brankovic et al. 1994; Ferranti et al. 1994; Brankovic and Palmer 1997; Mason et al. 1999). Since model simulations forced with observed SSTs provide an indication of model performance assuming perfect SST forecasts, estimates of the skill of operational model predictions are generally overestimated, and model systematic errors introduced by the predicted SSTs may not be estimated at all. It is important to know what uncertainties in the forecasts of seasonal climate result from imperfect SST forecasts (Barnett 1995).
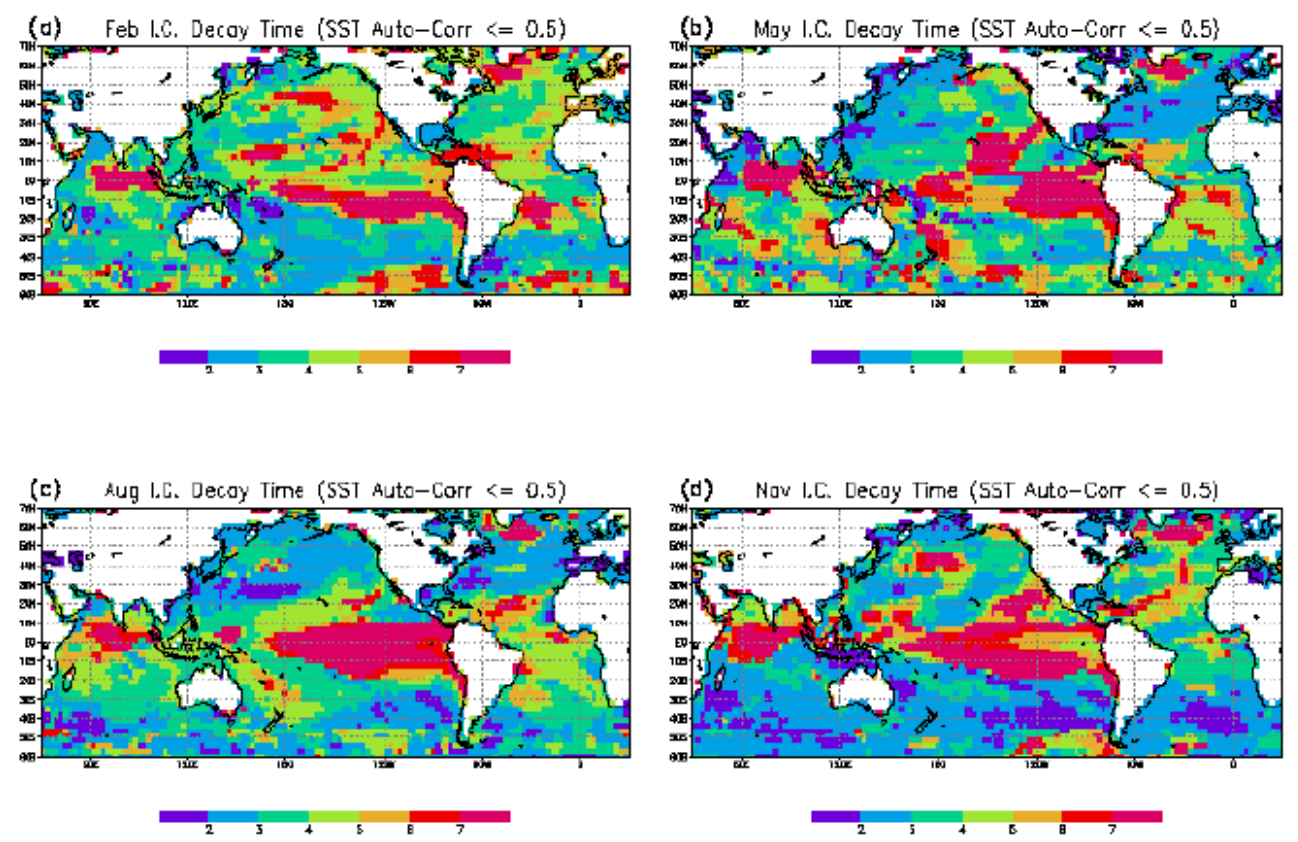

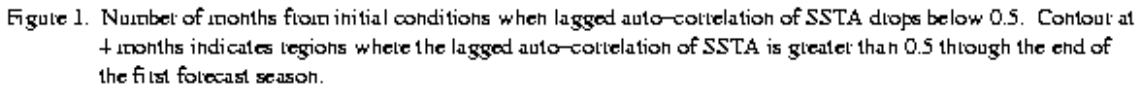

In this paper, the contributions of imperfect SST forecasts to seasonal forecast uncertainties are investigated. The focus is on identifying possible causes for loss of skill in forecasting precipitation that may arise from using persisted SSTAs as forcing for dynamical atmospheric models. Because of its large social implications for many parts of the world, attention is focused on potential prediction skill of precipitation. 
Comparisons between the precipitation hindcasts and simulations are used to identify where skill is lost as a result of imperfect SST forecasts, and hence to identify key ocean areas where short lead-time SST forecasts need to be improved.

\section{Data and methods}

\subsection{Model and Experimental Design}

The ensemble model experiments used in this analysis were run using the ECHAM3.6 atmospheric general circulation model (AGCM), configured at spectral truncation T42 (approximately $2.8^{\circ}$ horizontal resolution) and with 18 vertical levels. Further details of this AGCM can be found in DKRZ (1992).

Two sets of ensembles were created. "Simulation" runs were generated by forcing the AGCM with observed simultaneous monthly-mean SSTs. An ensemble of 10 simulation runs is available for the period 1950? present. The initial conditions of the ensemble members differed from each other by one model-day of weather when the simulation began with 1949. The integrations proceeded continuously from 1949 to present day conditions, and the first year was discarded. "Hindcast" runs refer to forecasts that were made retrospectively for the purpose of assessing the forecast method (Ward et al. 1993). The hindcasts were forced by persisting the observed SSTA from one month through the following 3-month season. The persisted anomaly is added to the evolving climatological cycle of SST to obtain the full SST forcing. For the hindcast runs, 5 member ensembles were generated using initial conditions from the ensemble members of the simulation set. Hindcast ensembles were made for 4 non-overlapping seasons: the March ? May (MAM) hindcasts use persisted SSTA from February; the June ? August (JJA) hindcasts use persisted SSTA from May; the September ? November (SON) hindcasts use persisted SSTA from August; and, the December ? February (DJF) hindcasts use persisted SSTA from November. These seasonal hindcasts cover the 27-year period 1970? 1996 (26-year period 1970/71 ? 1996/97 for DJF). 
The analysis period is that common to both sets of AGCM runs: 1970?1996. This 27-year long record is used to identify regions that are sensitive to errors introduced by persisted SSTA forcing of the AGCM. The performance analysis of both ensemble sets considers the ensemble-mean response of the model. Since the hindcasts have only 5 members, while the simulations contain 10 members, for the sake of a fairer comparison the ensemble-mean of the simulation was calculated using only 5 of the available members. A large pool of other potential combinations of 5 ensemble members for the simulations provides an estimate of the range in skill due to the model's uncertainty in the ensemble-mean response when the number of ensemble members is insufficient to resolve the forecast probability distribution (Kumar et al 2001). The results in Section 3 shown from the random selection of 5 simulation members are representative of the median in the range of skill levels locally.

\subsection{Observational Data}

SST. The Reynold's observed SST dataset from the Climate Prediction Center of the National Weather Service (Smith et al. 1996) was used as boundary forcing in the AGCM experiments. These SST data are provided as monthly averages on a $2^{\circ}$ grid. The data were interpolated spatially to the effective grid resolution of T42, and then linearly interpolated to daily values as the AGCM stepped through the integrations.

Precipitation. The precipitation verification data were obtained from the Climate Research Unit of the University of East Anglia. The observed climatological data covering the 1961 ? 1990 period comes from up to 19,800 stations, which are mapped onto a $0.5^{\circ}$ grid over land treating elevation dependency explicitly. Grid points are filled in using thin plate splines in regions where rain gauges are missing or sparse (New et al. 1999). The monthly anomalies, from a less dense network of stations, are estimated locally and then combined with the high-resolution climatology to obtain the total precipitation fields. In regions of sparse data coverage of anomalies, most notably over parts of central Africa and the Middle East, angular distance weighting was used to interpolate the values spatially (New et al, 2000). The final gridded data 
set contains no missing data. The high resolution data were up-scaled to the T42 grid for comparison with the AGCM precipitation fields.

\section{Results}

\subsection{Simulation v hindcast skill}

In an operational forecast setting, the skill of rainfall predictions from an AGCM is unlikely to be as great as the potential prediction skill estimated from simulations forced with the simultaneous observed SSTs. The loss of skill in the operational context is greatest in regions where the climate is sensitive to errors in predicted SST anomalies. The sensitivity of an AGCM to persisted SST anomalies, can be estimated by comparing the ensemble-mean anomaly correlations from the simulation to those from the hindcast. To the extent that the magnitude or structure of dynamically important SST anomalies evolves through the season in any particular year, persisted SST anomalies will not accurately reflect the observed forcing of the system. An erroneous signal will then be generated in the AGCM's climate, and a loss of skill will be reflected in weakened anomaly correlations for the hindcasts compared to the simulations.

The anomaly correlations for the simulations indicate that potential prediction skill is high in only very few regions for any one season in this model (Fig. 2a-d, top panels). This weakness in the predictability of precipitation is a typical property of current state-of-the-art AGCMs (e.g. Peng et al. 2000), and may be an inherent property of precipitation variability for much of the globe. Despite the poor skill globally, the tropics clearly display potential skill (Fig. 2a-d, top panels), with the highest correlations typically found over northern South America, tropical Africa, and the Indonesia region.

In Fig. 2a-d, the bottom panels show the anomaly correlations for the hindcasts. The same coherent regions of skill identified in the simulations are, in general, captured by the persisted SSTA hindcasts, which suggests that using persisted SSTA constitutes a reasonable SST prediction for one-season lead time. However, even 

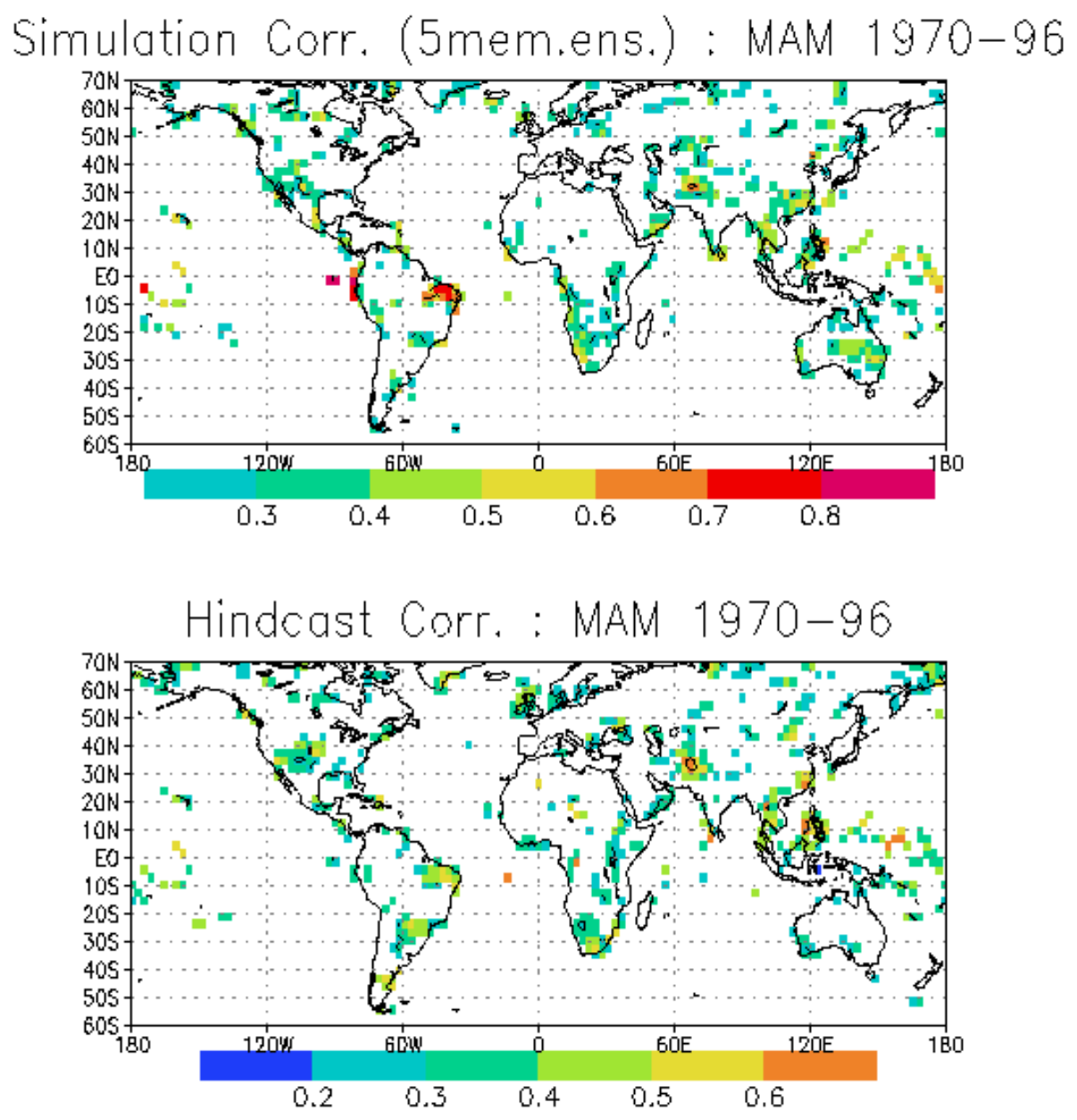

\footnotetext{
Figule 2a. A hounaly collelation 1naps connpaling pleci pitation a hoinal ies flon obselvations agai hst those floun AGCM expelingehts (uppel panel: sirnulation tuhs; lowel' panel: hindeast tuns) fol MAM 1970-1996. Contoul intelval is 0.2. Shaded aleas indicate loeal statistical significance exceeding $90 \%$ confidence.
}

though the hindcasts replicate much of the regional prediction skill, the anomaly correlation coefficients are often significantly less than were obtained with the simulations. In some cases, such as over western Africa in June ? August and over eastern Africa in September? November, large and coherent regions in which the 

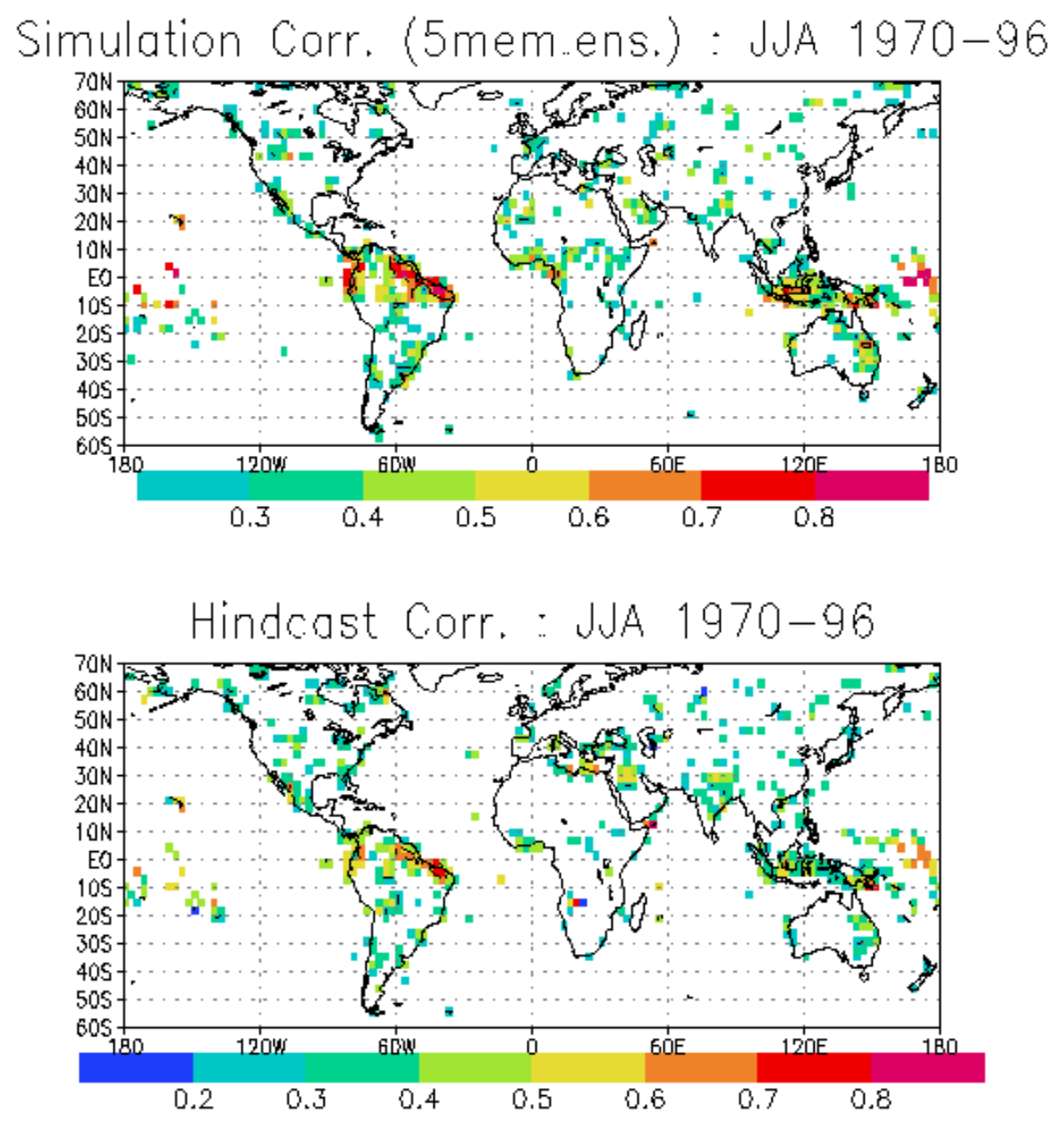

Figule 2b. Sane as Figule 2a, but fol JJA 1970-1996.

model had good simulation skill have weak hindcast skill. The loss of prediction skill over these two areas is examined in further detail below. 
Correlations Significant of $90 \% \mathrm{CL}$
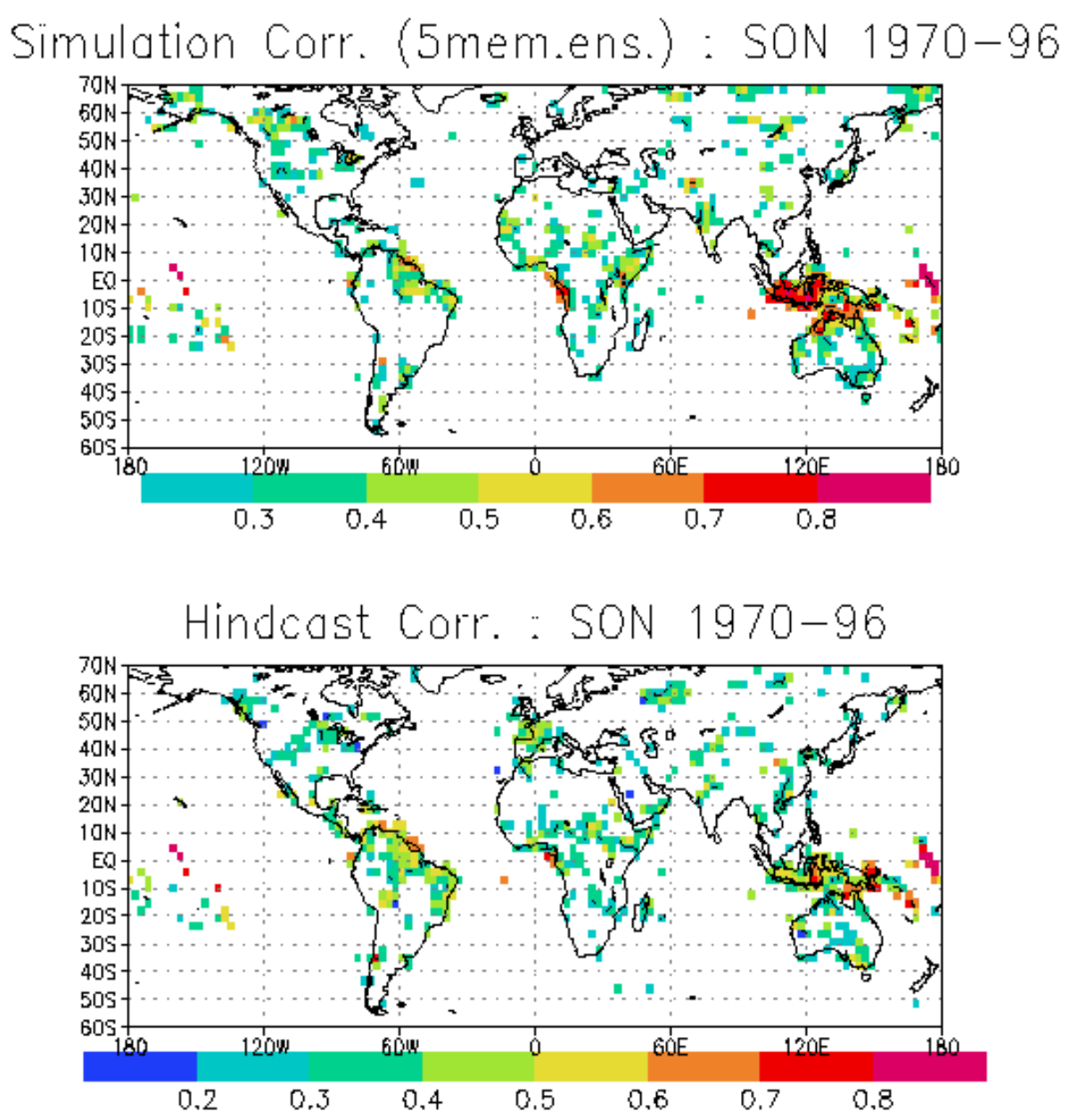

Figule 2c. Sance as Figule 2a, encept for SON 1970-1996. 
Correlations Significant at $907 \mathrm{CL}$

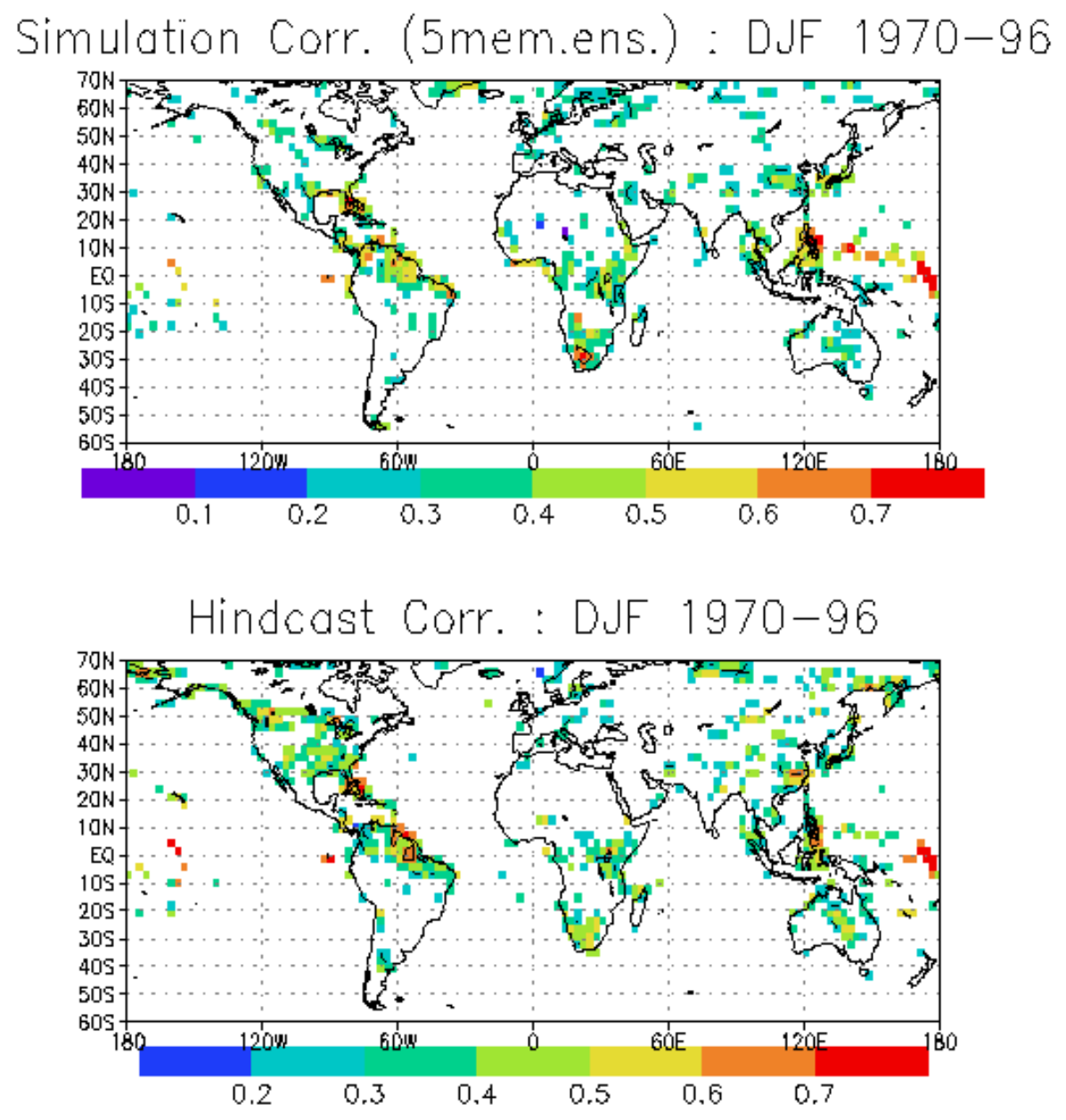

Figule 2d. Salte as Figule 2a, except fol DJF 1970h1-199697. 


\subsection{Changes in the model's climate signal and noise}

In addition to reductions in skill because of erroneous boundary forcing, forecast quality may be adversely affected by changes in characteristics of the model climatology under different approaches to prescribing SSTs. Relative to simulations forced with the actual simultaneous observed SST anomalies, the climate predictions may contain systematic biases in the model's local signal and noise characteristics.

Prediction biases in the seasonal response of the model can impact profoundly the interpretation of the predicted anomalies. The model's ensemble distribution for a particular season and year acquires meaning only relative to the climatological response of the ensemble members over many previous years for that same season. Thus the ensemble distribution for a particular season should be interpreted relative to historical runs that were subject to a similar boundary forcing strategy. Examples given below illustrate how differences in the model's response could be misinterpreted if a prediction forced with persisted SST anomalies were judged relative to the response characteristics of the simulation runs.

Signal and noise are two characteristics typically used to describe model response. In terms of the ensemble distribution, the signal represents the mean shift of the distribution, while the noise represents the spread of possible outcomes about that mean response. For an AGCM the model signal can be estimated by the ensemblemean variance, which represents the model's repeatable response to a given SST boundary condition (i.e. that in a particular season and year), averaged over many years (Anderson and Stern, 1996; Zwiers, 1996; Rowell, 1998). The signal, or externally forced variance, is defined here as:

$$
?_{\text {ext }}^{2}=\frac{1}{(n ? 1)} ?_{i ? 1}^{n}\left(A_{i} ? ? A\right\}^{2},
$$

where $A_{i}$ is the ensemble-mean value for a particular year, $i$, which summed over all $n$ years, gives the ensemble-mean climatological value, ?A?. Model noise, or internally forced variance, refers to the average deviation of the individual ensemble members from the model's mean response. Noise is defined here as: 


$$
?_{\text {int }}^{2} ? \frac{1}{(n ? 1)} \stackrel{?}{i ? 1}_{?}^{n} \stackrel{?}{?} \frac{1}{m} \stackrel{m}{j} ? 1^{m} ?_{i j} ? A_{i}{ }^{2} \stackrel{?}{?},
$$

where $a_{i j}$ represents the individual ensemble member, $j$, for a particular year, $i$, which summed over all ensemble members, $m$, leads to the ensemble mean value, $A_{i}$.

The time-averaged signal-to-noise ratio is often used to represent model potential predictability (Madden, 1976; Lau, 1985; Chervin, 1986; Shea and Madden, 1990; Rowell, 1995). When the external variance forced by the boundary conditions exceeds the internal variance of the atmosphere, it implies that a deterministic signal can be discerned above the noise in the system and may be predictable. This type of potential predictability does not necessarily indicate skill: the model may respond to boundary forcing in a manner inconsistent with observations. In nature, it is not possible to separate the boundary forced 'signal' from the internal 'noise' of the atmosphere, because observations yield only one realization. Thus, these components of the variability must be approximated using an ensemble of AGCM integrations. As the number of ensemble members increases, this approximation should become better, although the signal-to-noise ratio will remain specific to the particular AGCM. With the small number of ensemble members used for the experiments in this paper, the noise patterns are likely to be partly projected onto the signal patterns (Rowell, 1995, Venzke, 1999), but the assumption here is that this contamination is similar enough between the two experiments that comparisons are valid.

Figures $3 ? 5$ show the average signal-to-noise characteristics of the simulation and hindcast experiments for the individual tropical ocean basins in each of the four seasons. One cannot assume a priori how the signal and noise characteristics will change locally subject to predicted SSTA. Overall, these characteristics remain similar to those seen in the simulation runs. Of particular interest are the cases for 

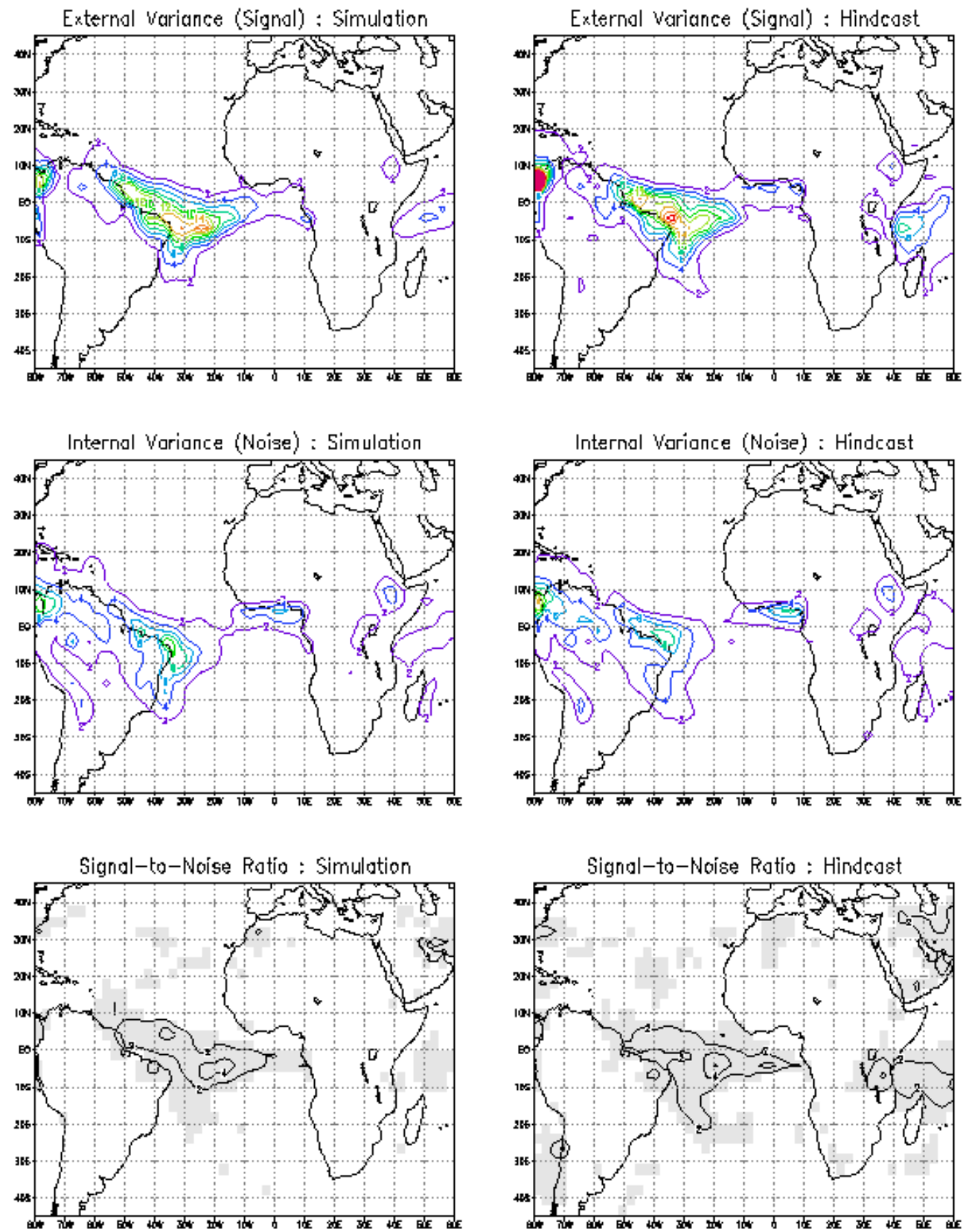

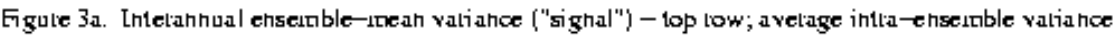
("hoise") - -riddle tow; and tatio of sighal to hoise - bottoin tow fol singulation tuhs (left colunh) and hindeast luns (tight colunn) ovel the tlopical Atlantic Deean fol MAM 1970-19\%.

which the signal changes noticeably but the strength and pattern of the noise fields remains similar between the simulation and hindcast runs. For example, over the tropical Atlantic in JJA (Fig. 3b), the AGCM responds much more dramatically to the persisted SSTAs than to the simultaneous anomalies, but the overall internal variance 

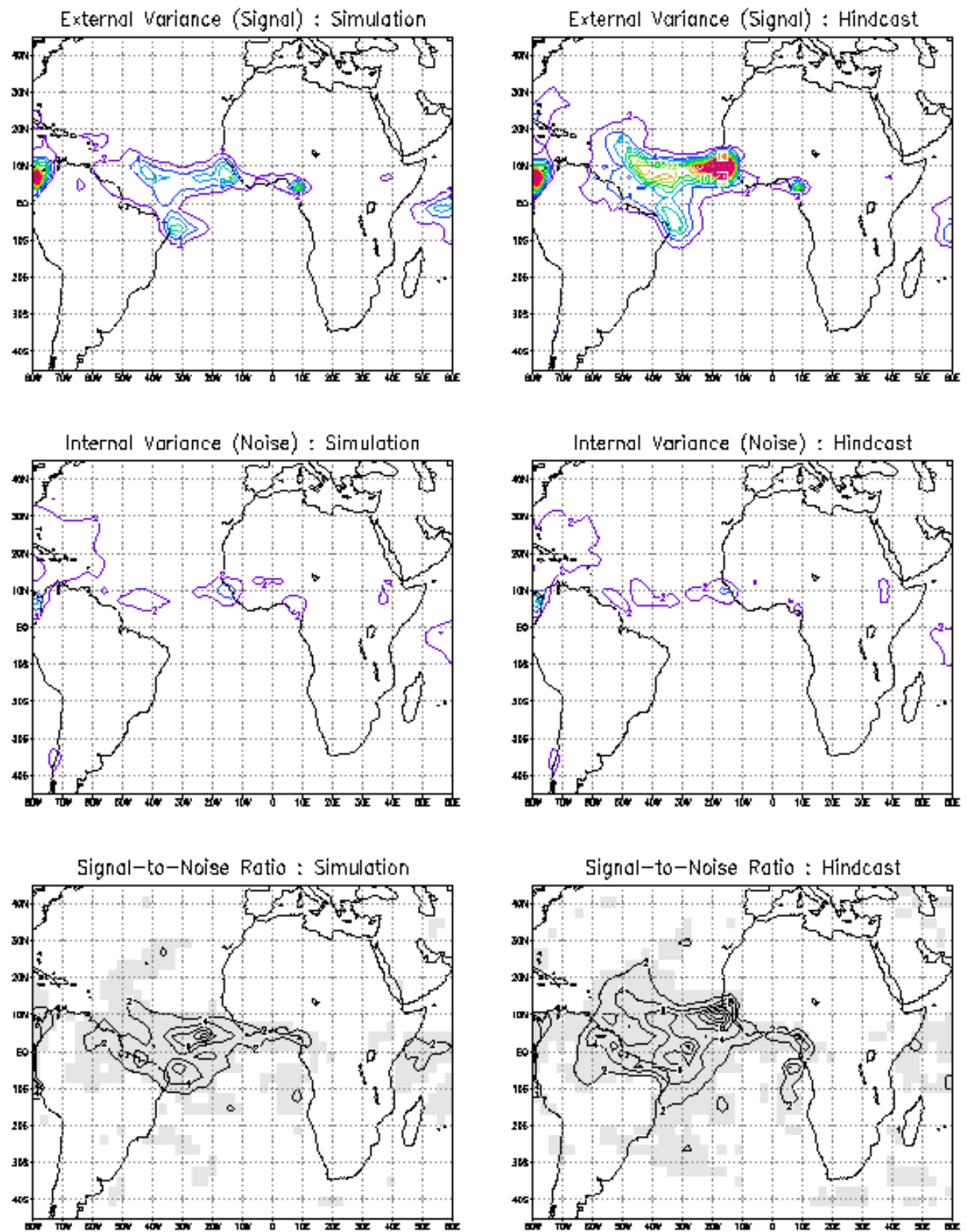

Figule 3b. Sanc as Figule 3a, except fol JJA 1970-1996.

remains effectively unchanged. The strengthened signal in the hindcast experiment leads to an increase in the signal-to-noise ratio over parts of coastal western Africa by a factor of 5 or more compared to the simulation (Fig 3b, bottom row). Similarly, the external variance for SON over the Indian Ocean is strengthened given the persisted 

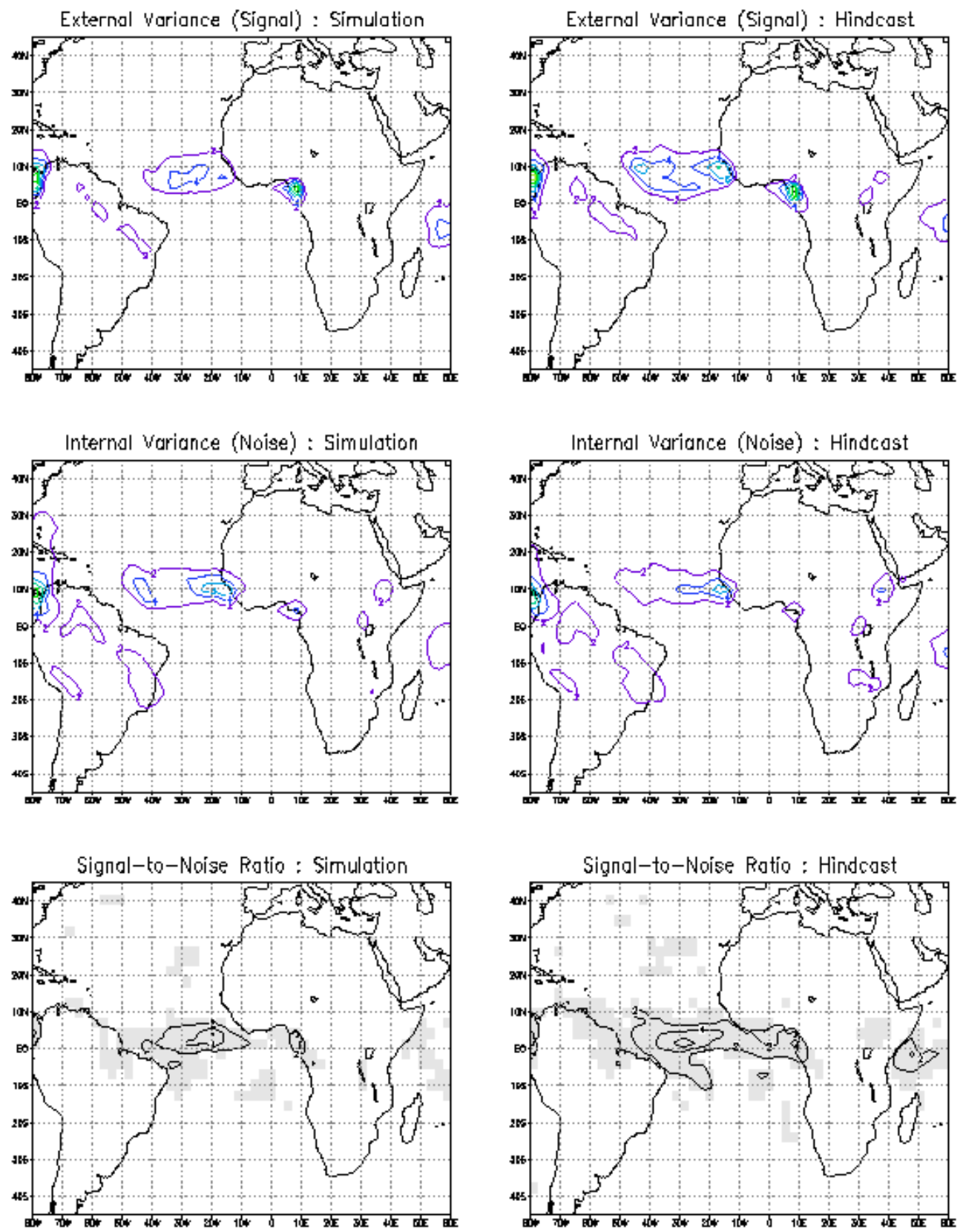

Figule 3c. Sane as Figule 3a, except fol SON 1970-1996.

SSTA (Fig. 4c, upper row), particularly in the Indonesian region, while the overall magnitude of the internal variance does not change (Fig. 4c, middle row). Again, the signal-to-noise ratio is greater in the hindcast experiment, particularly towards the eastern and western edges of the Indian Ocean basin (Fig 4c, bottom row). 

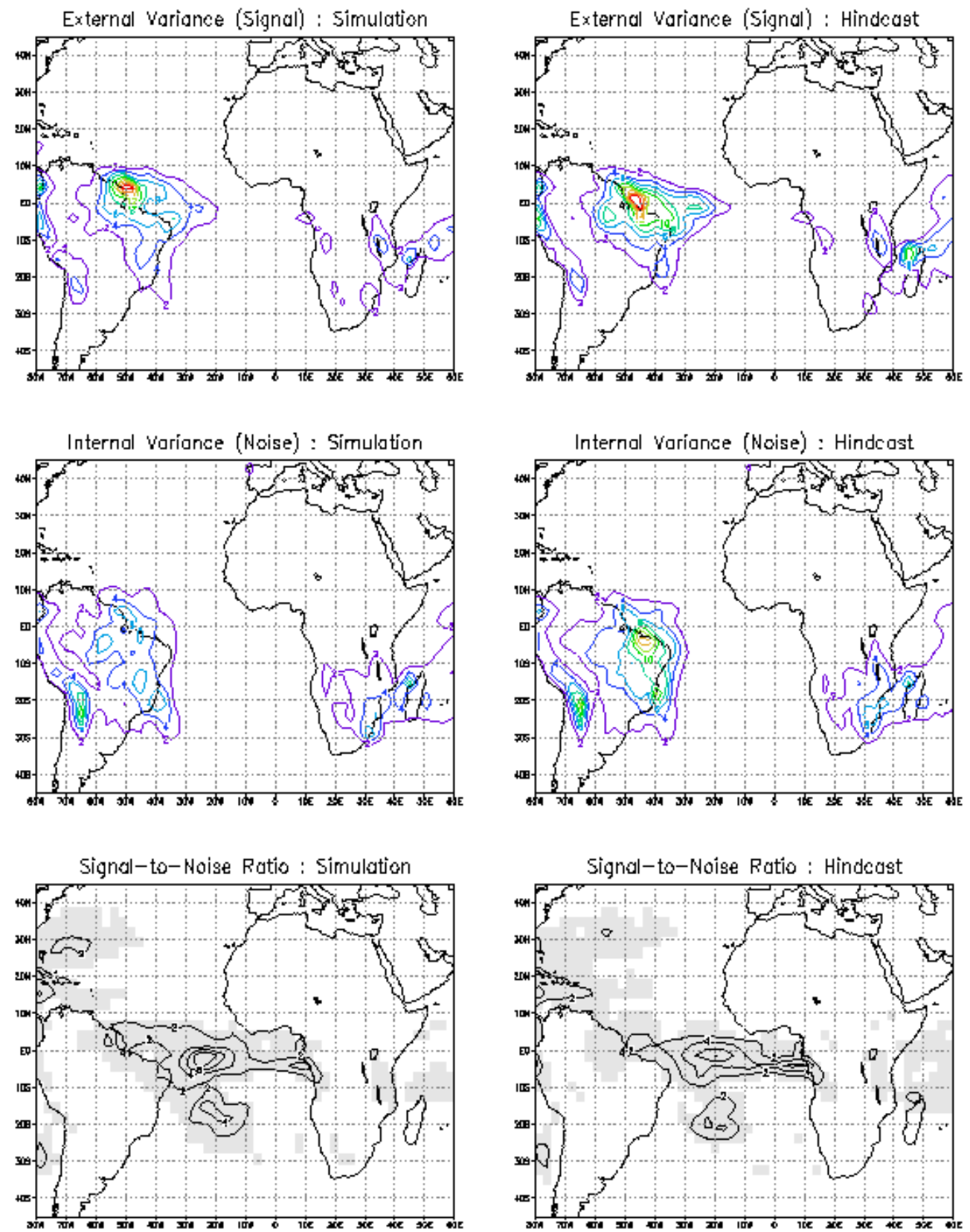

Figule 3d. Sane as Figule 3a, encept fol DJE 1970h1-1996/97.

These biases in both the strength and placement of the hindcast signal, relative to that from the simulations, must result at least in part from systematic errors in the characteristics of the SSTAs prescribed in the hindcasts. How SST errors relate physically to errors in the model's climate response is explored in the following 

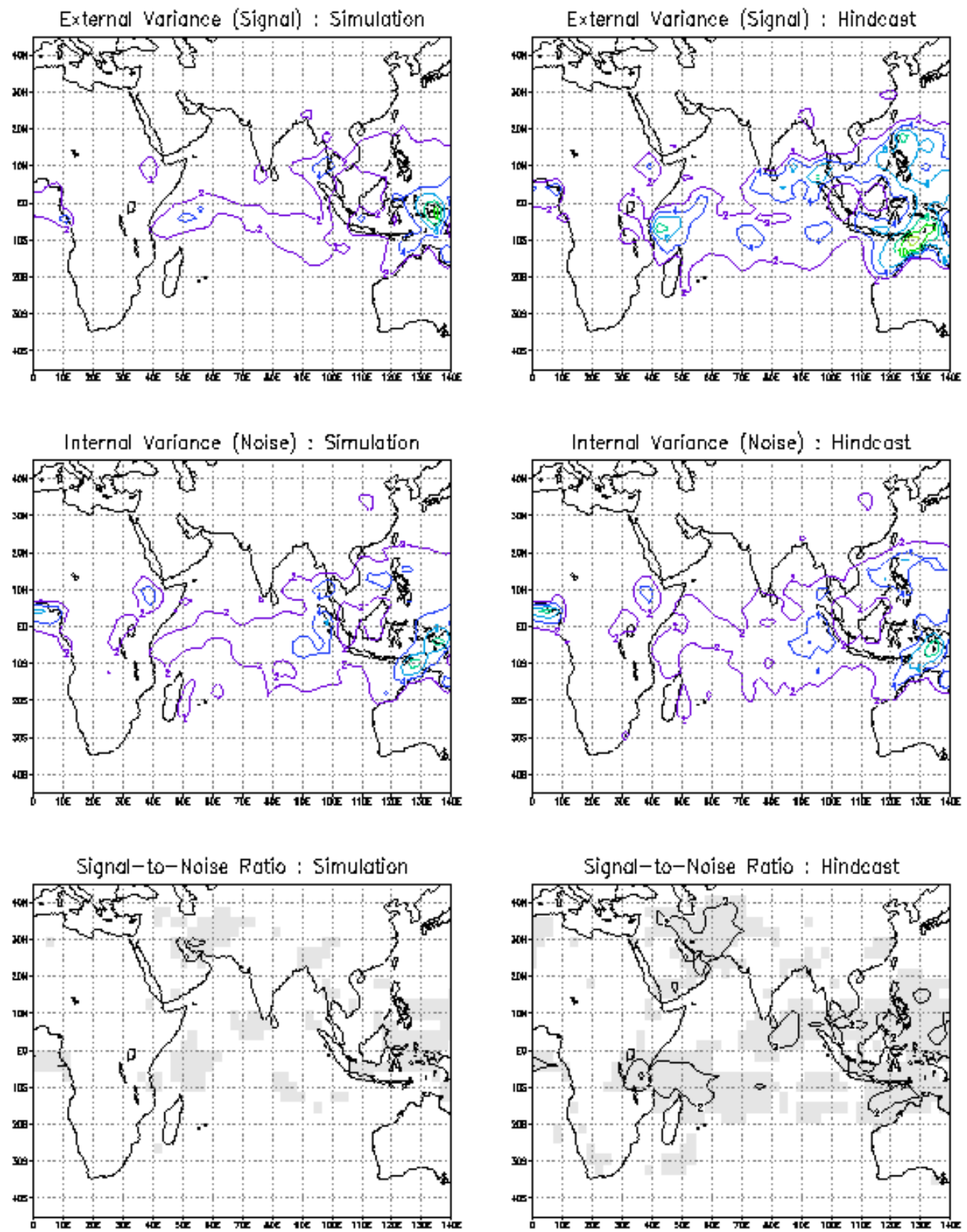

Figule ta. Sane as Figule 3a, encept ovel the Lndian Ocean fol MAM 1970-1996.

section for the two case studies highlighted above: western Africa in JJA and eastern Africa and Indonesia for SON. 

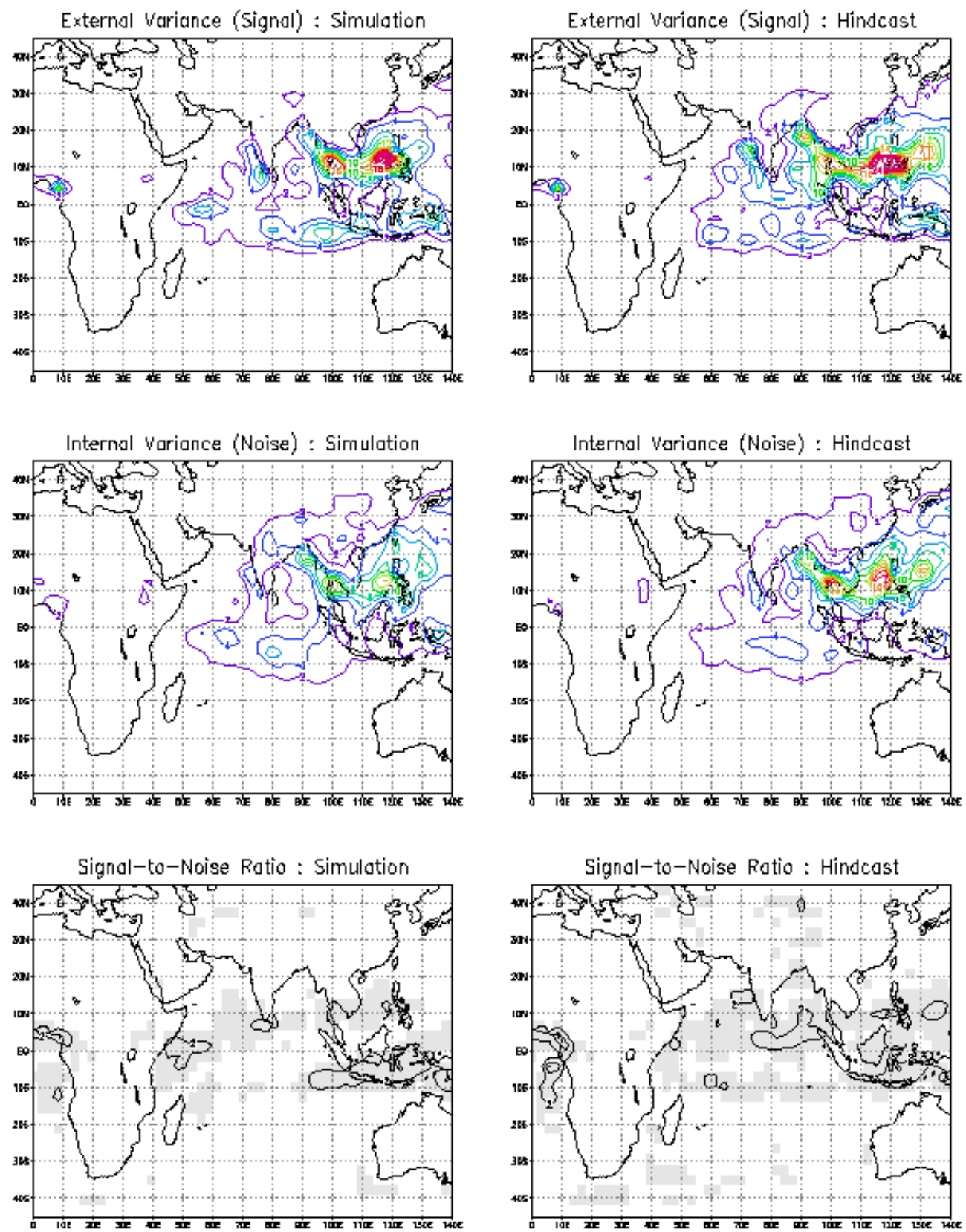

Eigule +b. Sarne as Eigule 3a, except ovel Lndian Qeean fol JJA 1970-1996. 

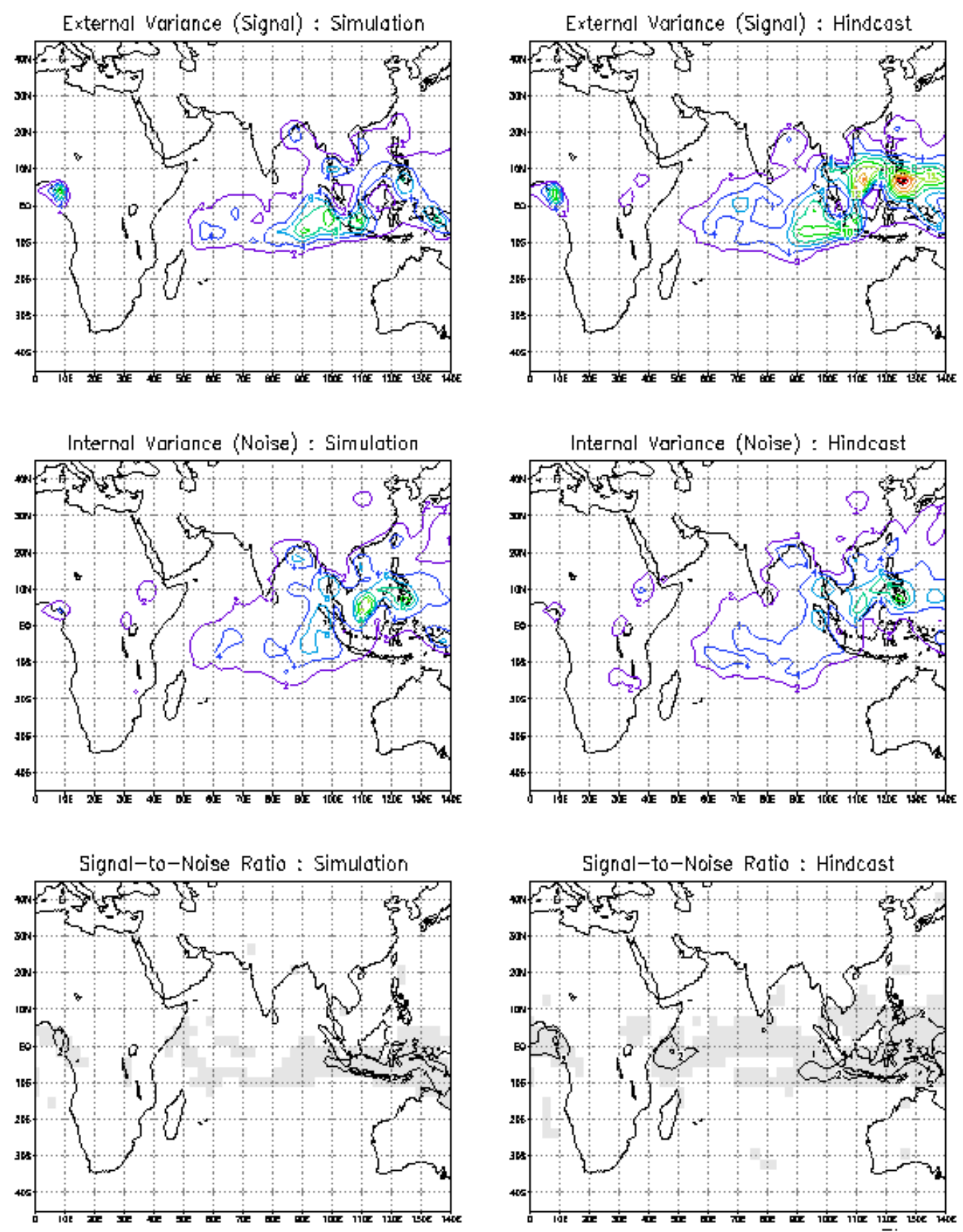

Eigute te. Sane as Figule 3a, encept ovel Lndian Ocean fol SON 1970-1996. 

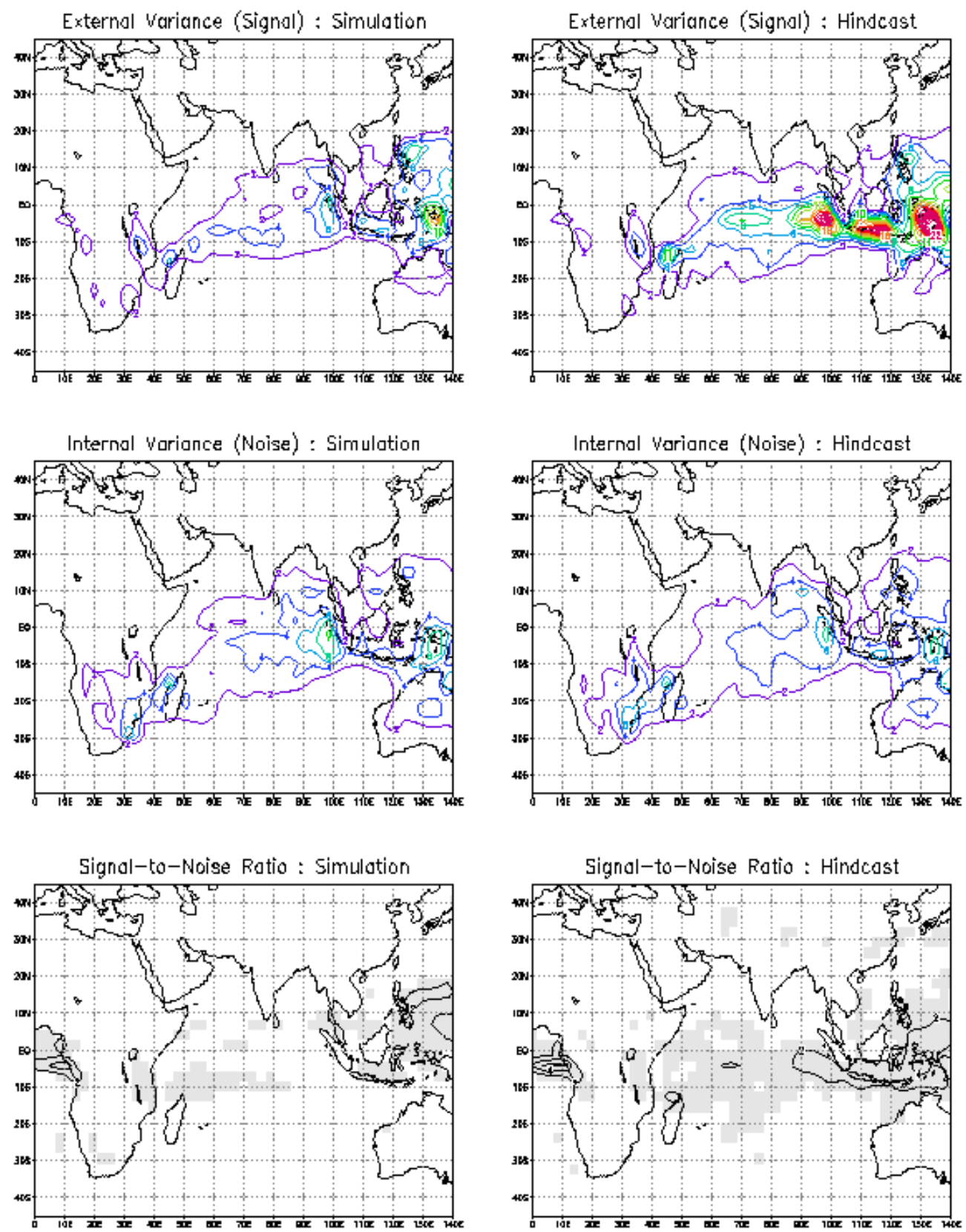

Eigule td. Sarte as Figule 3a, except ovel Lndian Qeean fol DJF 1970/71-1996/97. 

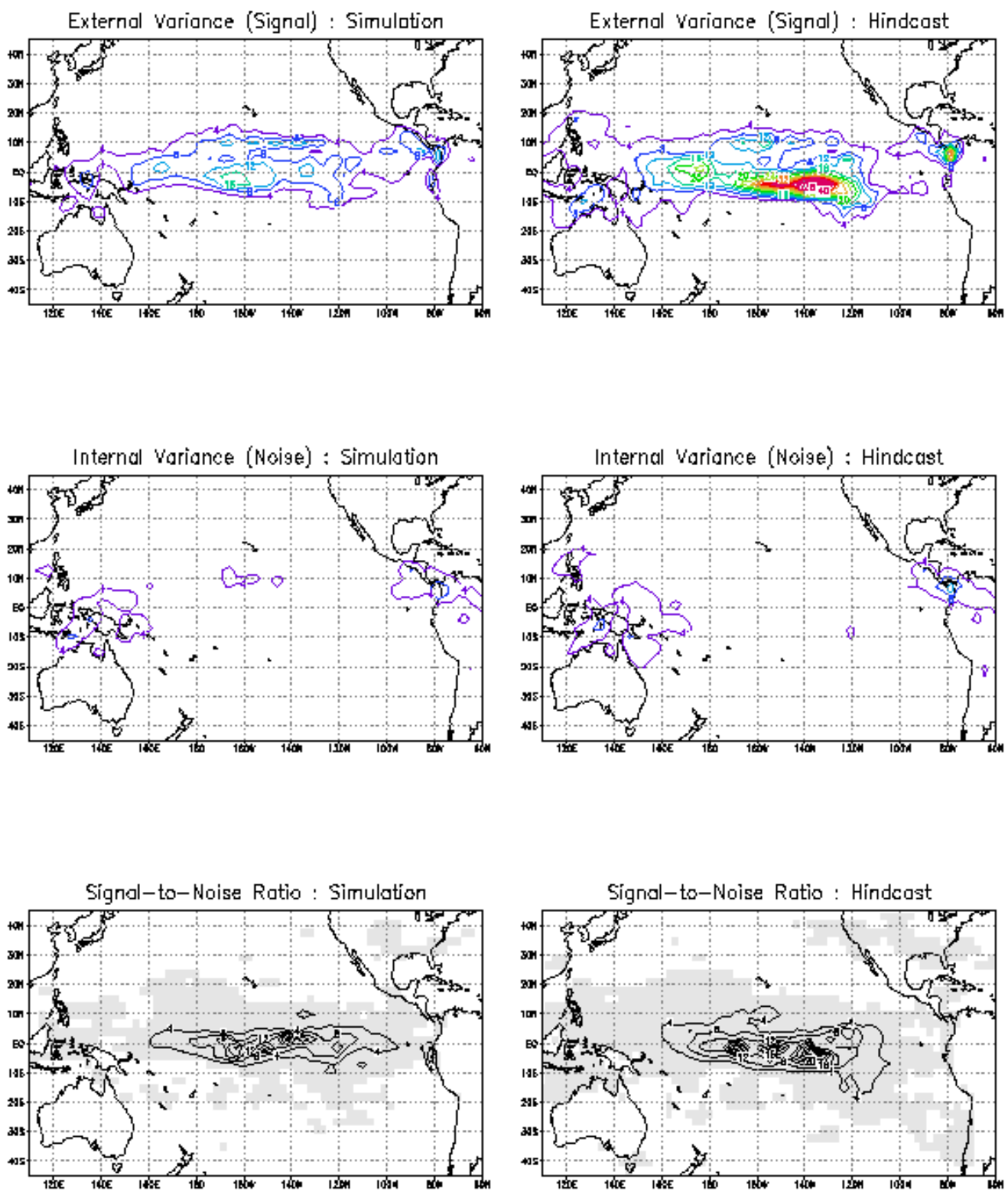

Figule Sa. Salne as Figule 3a, encept ovel Pacific Ocean fol MAM 1970-1996. 

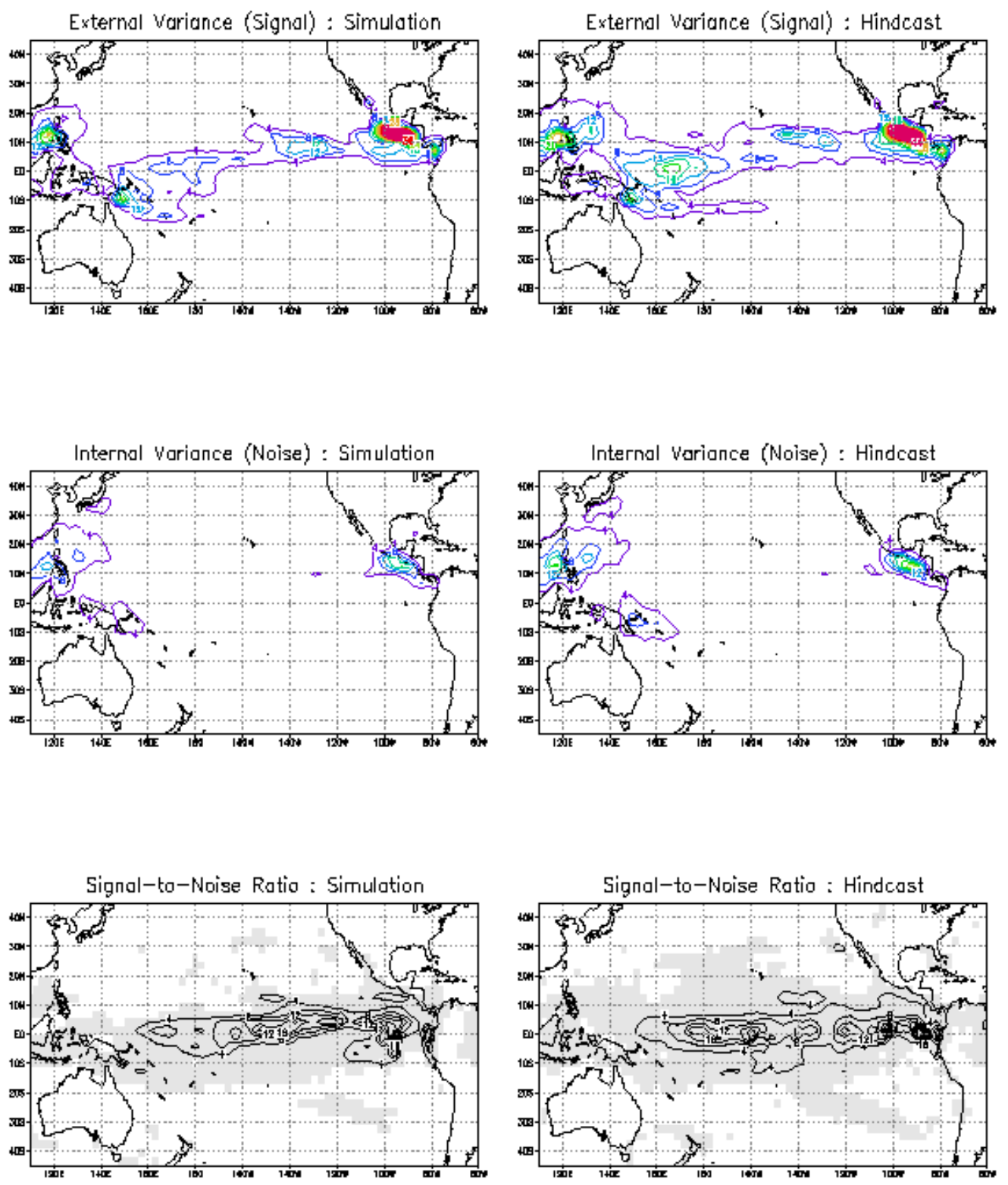

Eigule Sb. Sane as Eigule 3a, except ovel Pacific Ocean for JJA 1970-1996. 

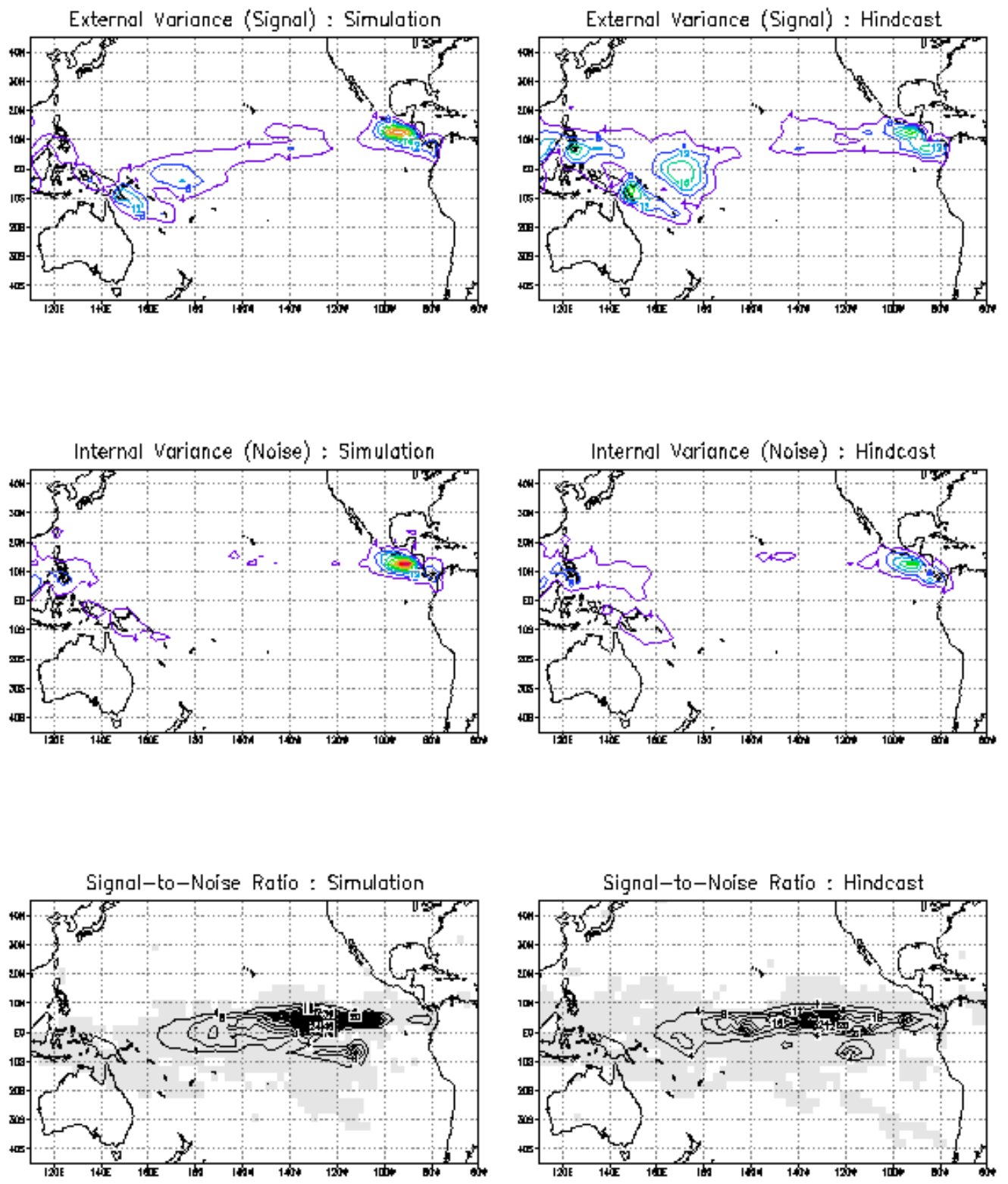

Figule Sc. Sane as Figule 3a, except ovel Pacific Qcean for SON 1970-1996. 

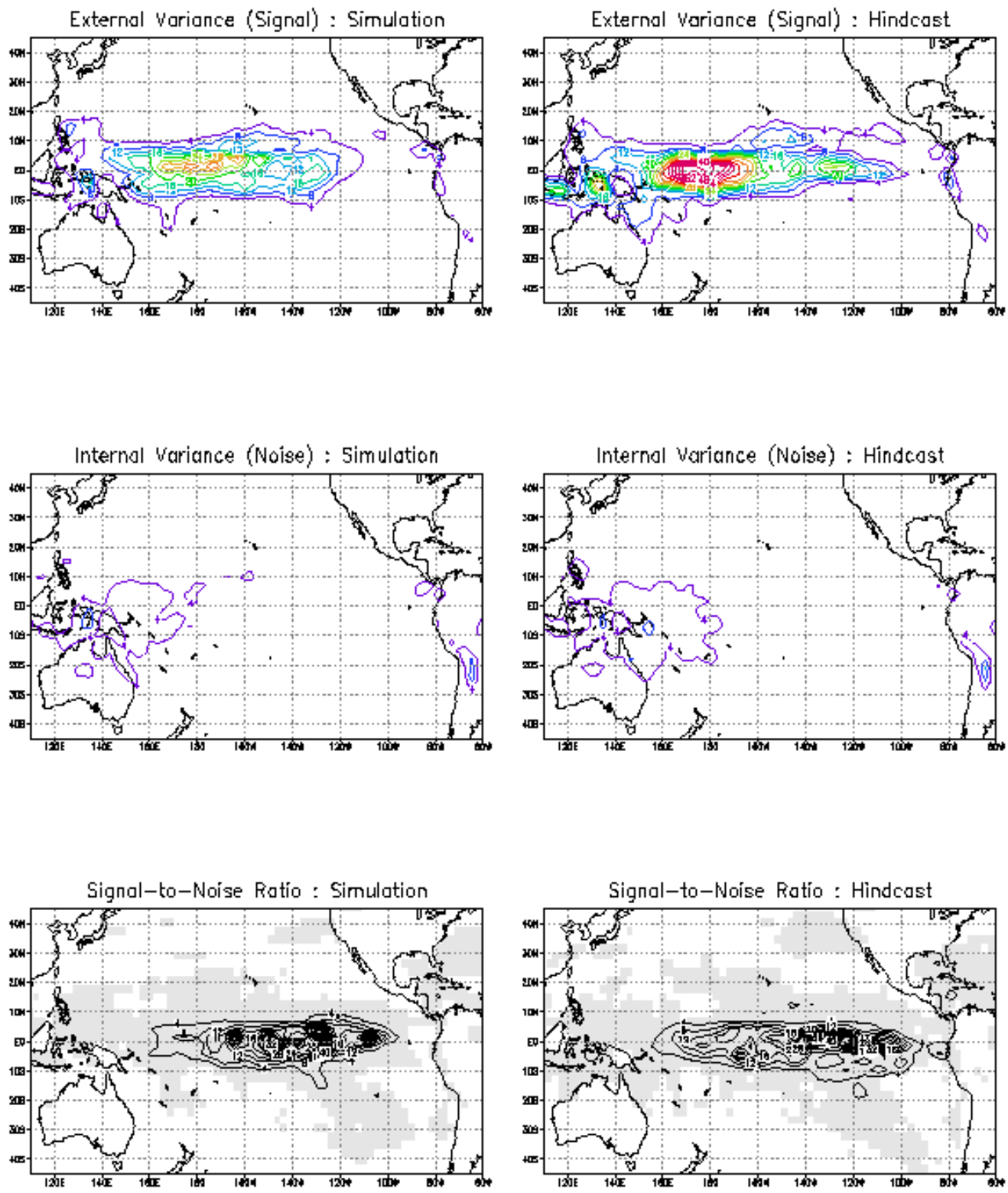

Figule Sd. Saute as Figule 3a, except ovel Pacific Ocean fol DJF 1970h1-199697. 


\subsection{Case Studies}

\subsubsection{JJA ? Western Africa and the tropical Atlantic Ocean}

Western Africa during the JJA season exhibits one of the most severe examples of loss in prediction skill using persisted SSTA (Figure 2b). The simulation using the actual SSTA demonstrates statistically significant skill over much of western Africa, particularly over the Gulf of Guinea region. When predicting JJA precipitation using persisted SSTA from May observations, the size of the region over which there is prediction skill decreases greatly, and for the small region of remaining skill, the anomaly correlation is 20 ? $50 \%$ weaker than that of the simulations.

As a first order approximation of the systematic SSTA errors resulting in this loss of prediction skill, canonical correlation analysis (CCA) was applied to the seasonally averaged difference fields of SST and rainfall. The difference fields are defined as the actual minus the predicted (i.e. persisted) SSTA and as the ensemble mean simulation rainfall minus the hindcast rainfall. The CCA maximizes correlation between the two fields using weighted combinations of the first $5 \mathrm{EOFs}$ from each of the difference fields. For the SST difference, dSST, the EOFs were constructed using covariance matrices, which emphasize the magnitude of the errors in the SST forcing. For the precipitation difference field, $\mathrm{dPCP}$, correlation matrices were used for the EOFs, which highlight any systematic shift in rainfall patterns regardless of the strength of the differences.

The first CCA mode shows a meridional structure in both SSTA and precipitation (over land) differences (Fig. 6). This structure implies that when predicted SSTA is too warm in the equatorial region and too cool off the west coast at approximately 10 ? $\mathrm{N}$ there is a southward shift of the AGCM precipitation response. Using persisted SSTA with this error pattern, more rainfall appears in the Gulf of Guinea region and less to the north than would have been simulated with the actual SSTA. The principal component time series of $\mathrm{dPCP}$ and $\mathrm{dSST}$ for this first CCA mode correlate at 0.84 and describe $15 \%$ of the $\mathrm{APCP}$ variance and $17 \%$ of the $\mathrm{dSST}$ variance. A similar pattern emerges from a CCA analysis of the actual precipitation variability related to SST variability in both the observations and the AGCM over this region (not shown), with similar correlation between the pattern time series, and a similar fraction of 


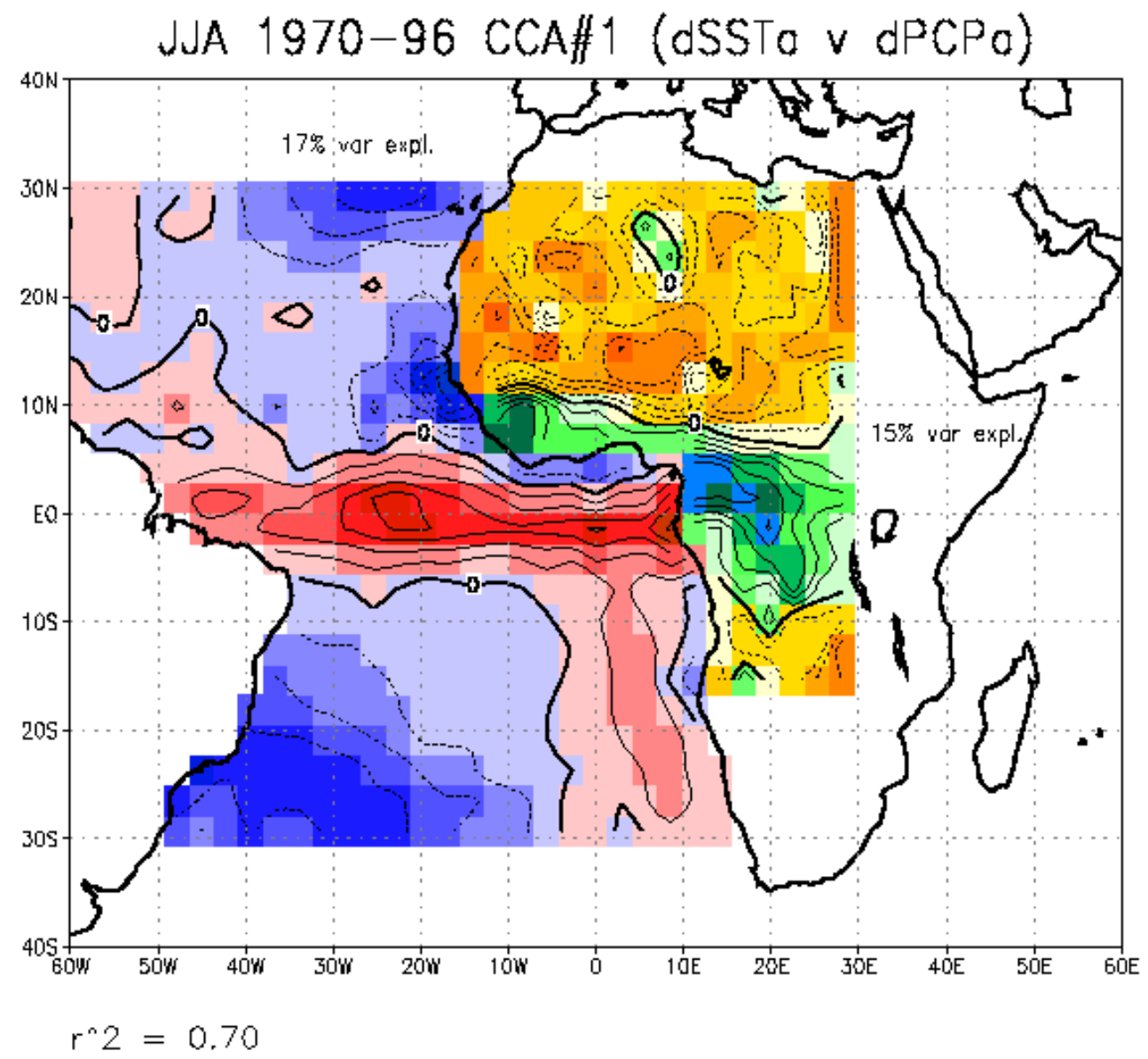

Figute 6. Filst node of Canonical Cottelation A nalysis showing dontinant patteth of plecipitation ettots genetaled by donninant patteth of SSTA ettol for JJA 1970-1996 ovel the tlopical Allanticl westelin Aftica tegion.

dSSTA = obselved JJA SSTA - pelsisted May SSTA $\mathrm{dPCP} a=$ sirnulated $\mathrm{PCP} a-$ hindeast $\mathrm{PCP} a$

Red (blue) shading ovel oean indieates positive (negative) ettols in SSTA and gleen (olange) shading ovel land indicastes positive (negative) plecipitation ettols. Maps ale invaliaht to change in ovelall sign.

variance explained. The similarity between the error and actual CCA analyses is not surprising because much of the precipitation variability for JJA in this region is governed by the anomalous position of the ITCZ over the Atlantic (Ward 1998). Climatologically, the ITCZ migrates northward in June ? August and reaches its northern-most latitude by the end of the season. If equatorial SST is warmer than 
normal, equatorial sea level pressure will be lower than normal, and anomalous equatorward flow will be induced. This anomalous tropical circulation causes the ITCZ to reside closer to the equator than normal for this season, bringing higher rainfall totals to the Gulf of Guinea region and lower rainfall over the Sahel (Lamb 1978a, 1978b; Lough 1986; Ward 1998).

Unfortunately, even though the first mode of the error fields is similar to the first mode of the full variability, this structure does not appear as a cleanly evolving mode during any particular JJA season. The intra-seasonal SSTA field in the tropical Atlantic contains considerable noise, fluctuating greatly from one month to the next, as reflected in the weak persistence of SSTA at this time of year (Fig. 1b). Methods used to predict tropical Atlantic SST have been unable to improve upon a forecast of persistence south of the equator for any season (Penland and Matravosa, 1998; Landman and Mason 2001; Repelli and Nobre, 2001).

The first CCA mode of the SSTA error is largely due to seasonal changes in local SSTA variance. In May, the SSTA variance shows a local maximum off the west coast of Africa at approximately $10^{?} \mathrm{~N}$ (Fig. 7a). The strength of the SSTAs in that region typically drops off dramatically by June, and remains negligible throughout JJA (Fig. 7b-d). Conversely, the equatorial variance of SSTA is small in May, but grows in June and July. Thus persisting May SSTA through JJA in the tropical Atlantic imposes SSTA signals that are likely to disappear, or at least weaken, in the coming forecast season north of the equator and does not specify signals that may develop during the forecast season on and to the south of the equator.

The difference in signal-to-noise ratios between the simulation and hindcast runs also may result in part from the seasonal changes in local SSTA variance. Due to the month-to-month noise in the tropical Atlantic SSTA, the equatorial variance of May SSTA is very similar to that of the JJA seasonal average (Fig. 7a vs. Fig. 7e), even though the SSTA variance of June and of July is stronger. Therefore, the stronger precipitation signal generated by the hindcast experiments (Fig. 3b) must be due to at least one of two possible causes. First, the presence of the stronger SSTA variance in May seen off the western coast of Africa (Fig. 7a) and known to be associated with the precipitation error between the two experiments (Fig. 6) may be overly influencing the JJA forecasts. In this case, merely damping the observed SSTA in that 

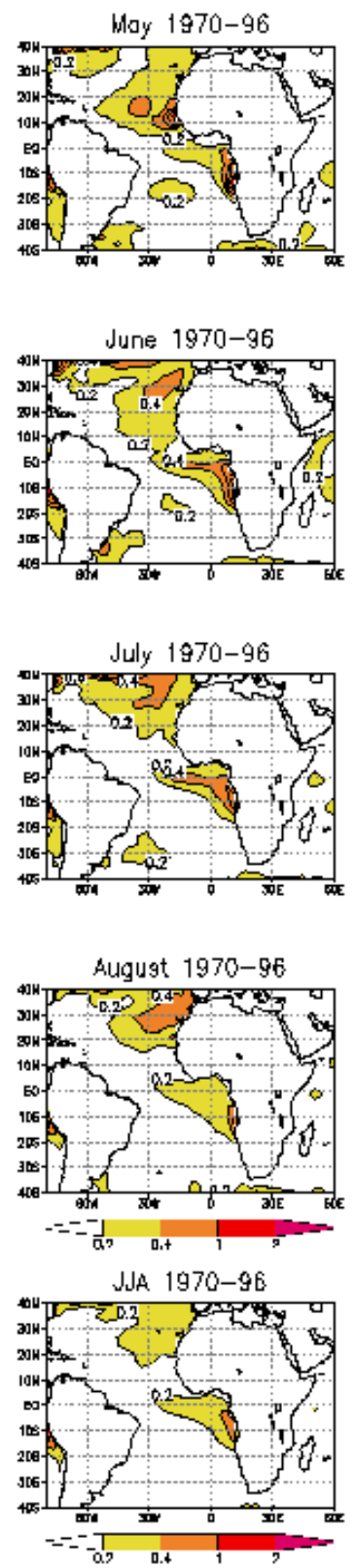

Figule 7. Yaliance of SSTA avelaged $1970-1996$. Units ale deglees $C^{\wedge} 2$. Contoul intelval is 0.2 .

region should bring the signal into better agreement with that of the simulation. Second, the tropical precipitation may be exhibiting a non-linear response to equatorial SSTA. The equatorial region exerts a significant influence on the differences in precipitation over the West Africa region (Fig. 6). If it is assumed that the equatorial SSTA dominates the precipitation variability and that precipitation anomalies are linearly related to SSTA, then the rainfall signals should be 
approximately equal if the SSTA variance is approximately equal in both experiments. But, such equivalence is not seen in the precipitation variance even though the variance fields of the prescribed seasonal SSTA are of similar magnitude in the equatorial region. These two hypotheses require explicit experimentation, however, before their relative impacts can be determined.

The sensitivity of the Atlantic ITCZ to errors in the SSTA also affects the rainfall signal over northern South America. However compared to western Africa, the simulation skill over South America is higher and covers a larger area so that a reduction in skill of similar magnitude to that exhibited over western Africa still leaves a substantial region with significant operational predictability under this method of SST prediction.

This case study has focussed on the season JJA for western Africa; however, JAS more accurately defines the rainy season for the Sahel region of western Africa. Ward et al. (1993) showed that AGCM predictions over the Sahel region for JAS improved when June SSTA was persisted instead of May SSTA. This result is consistent with the climatological evolution of SSTA variance patterns (Fig. 7). Thus shorter-lead forecasts made at the beginning of the season may prove more useful to decision makers. The main caveat from the preceding results is that potential prediction skill cannot currently be realized over this region from forecasts produced using May observations, or earlier, due to lack of forecast skill for equatorial/south tropical Atlantic SSTA.

\subsubsection{SON? Eastern Africa and the Indian Ocean}

Persisted SSTAs lead to significant reduction in skill over eastern Africa also, particularly over Kenya and northern Tanzania during the SON season (Fig. 2c). This season approximates the rainy season over the Greater Horn of Africa region, which peaks in October ? December (OND) for Kenya, being slightly earlier to the north and later to the south of Kenya as the ITCZ migrates southward during the end of the year. Variability of the OND rainy season over East Africa has a well-known statistical relationship with ENSO (Ropelewski and Halpert, 1987; Ogallo, 1988; Beltrando, 1990; Nicholson and Kim, 1997; Mason and Goddard, 2001). For the SOND season, the most robust teleconnection with ENSO is experienced in October 
and November when large-scale OLR anomalies are found over the Indian Ocean sector in phase with those over the tropical Pacific and out of phase with those over the Maritime continent (Mutai and Ward, 2000). In September the large-scale OLR structure does not appear over the Indian Ocean sector, possibly because of an influence of the seasonal background state of the atmosphere (Mutai and Ward 2000).

Although East Africa and the Indian Ocean sector do exhibit climate variability associated with ENSO, modeling studies have shown that appropriate changes in Indian Ocean SST are necessary to reproduce the correct rainfall variability over East Africa at the end of the year (Goddard and Graham, 1999). Using observational data alone, it is difficult to separate the importance of ENSO relative to that of the Indian Ocean since SST variability in these two ocean basins is highly correlated, with the tropical Pacific variability leading by approximately 3 months (e.g. Goddard and Graham, 1999; Venzke et al, 2000). When the forcings from the two basins are isolated, it can be shown that tropical Pacific SST anomalies applied to this AGCM without the ppropriate anomalies in the Indian Ocean lead to a rainfall response over East Africa opposite to that obtained with full global SST or even Indian Ocean SST anomalies alone (Goddard and Graham, 1999).

The 3-month lead time of tropical Pacific to Indian Ocean variability combined with the tendency of ENSO evolution to phase-lock to the seasonal cycle implies that SON is an important season for the evolution of SSTAs in the Indian Ocean basin. Generally, ENSO events first appear and begin to grow in the Northern Hemisphere Spring. Assuming that the lead-time between the Pacific and the Indian Ocean is relatively independent of the time of year, August SSTa in the Indian Ocean will reflect May or June conditions in the tropical Pacific when the ENSO event is just beginning to evolve. In November, the SSTA in the Indian Ocean will reflect August/September conditions in the tropical Pacific when the ENSO event is fairly mature. Thus rapid growth of ENSO, usually seen in the middle of the year, will appear as rapid development of SSTAs in the Indian Ocean only during the later part of the year (i.e. SON). Figure $8 \mathrm{a}$ illustrates the differences in persistence characteristics of the Indian Ocean and Pacific Ocean described above. By August, the SSTAs in the tropical Pacific are well established, and their persistence is high through the end of the year when the magnitude of ENSO SSTA usually peaks. On 

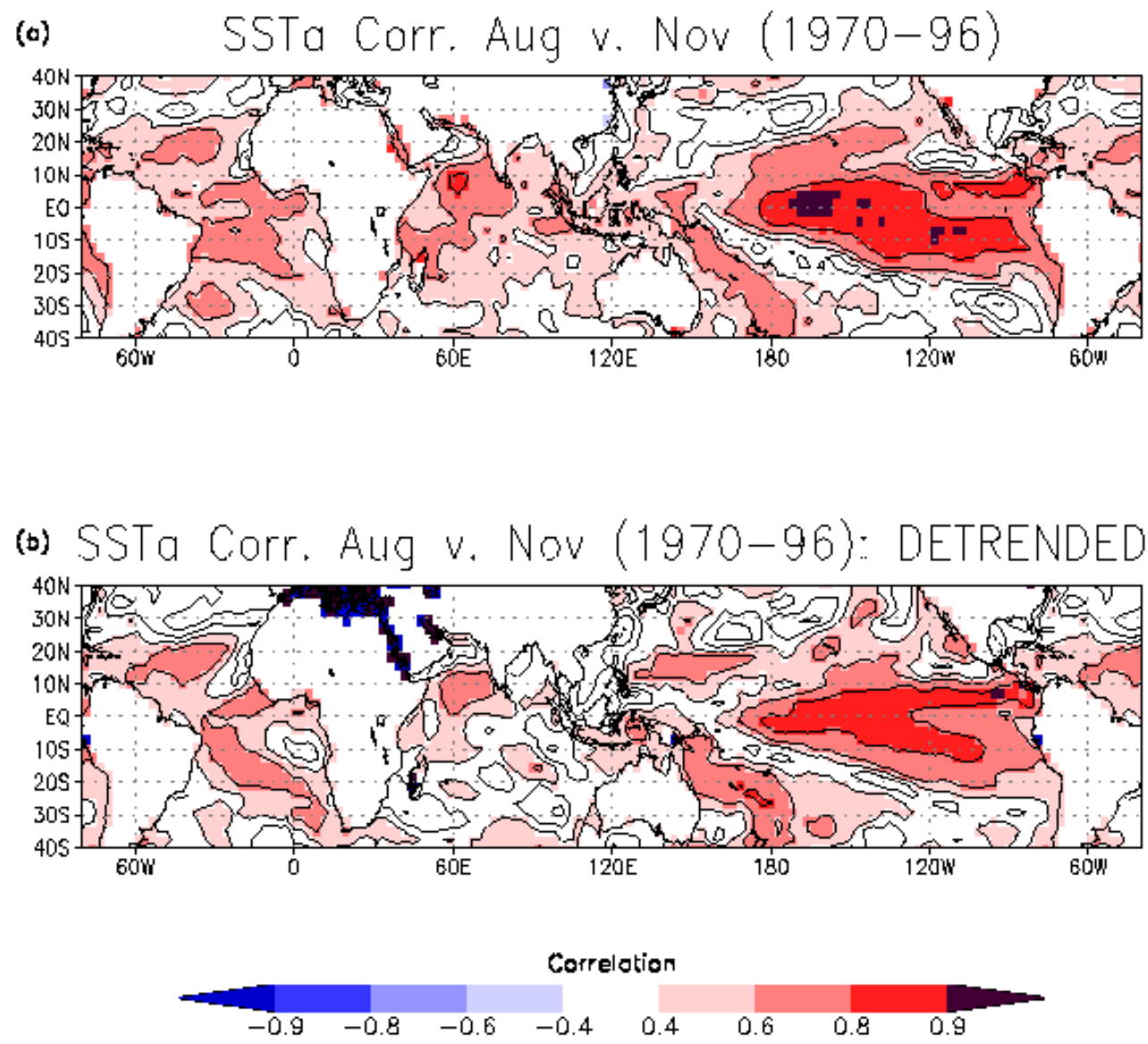

Figute 8. A homaly coltel ation between August SSTA and Noveunbet SSTA 1970-19\%, for (a) actual ahounalies; and (b) lineatly de-tiended anornalies. Contout intetval is 0.2 and 0 contout is dia wh heavily. Anounaly coltel ations exceeding $\mathrm{O} .+$ ale shaded.

the other hand, SSTA in the Indian Ocean is evolving at this time and neither the strength nor pattern of SSTA seen in August is persistent through SON. This is particularly clear when the linear trend that imparts some persistence through this season is removed (Fig. 8b). 


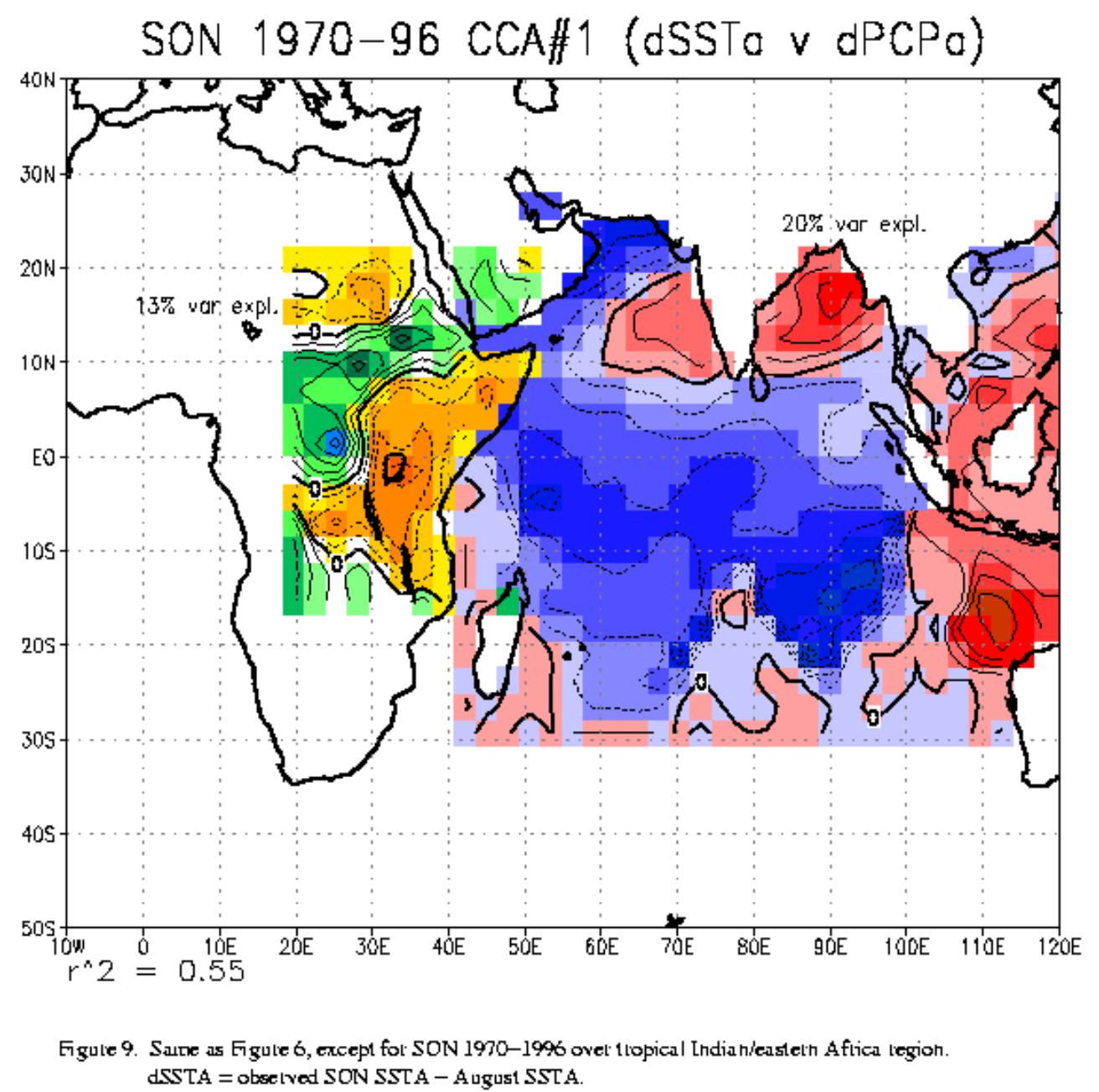

Because the Indian Ocean SSTA is central to reproducing rainfall variability over East Africa, the skill of an AGCM will be negatively impacted by the absence of this evolution in SSTA. The loss in skill seen over East Africa (Figure 2c-upper versus 2c-lower) appears primarily due to errors in prescribed SSTA over the Indian Ocean, as shown by the first CCA mode of the precipitation and SSTA difference fields (Fig. 9). When an $\mathrm{El} \mathrm{Ni}$ o event grows, positive SSTAs develop in the Indian Ocean that 
are larger in SON than in August. With the warm SSTA in the central Indian Ocean comes increased rainfall over East Africa, so persisting August SSTA through SON will lead to less rainfall over East Africa than seen in the simulations (Fig. 9). Notice also that the strongest loading in the SST pattern shown in Figure 9 coincides largely with the areas of weakest correlation of August versus November SSTA (Fig. 8b). Furthermore, the time series of the SSTA difference pattern correlates significantly to the change in NINO3.4 from August to SON $(r=0.45)(r=0.34$ for the actual SON NINO3.4 index). Both of the above findings suggest that rapid evolution of ENSO is related to the lack of persistence in the Indian Ocean during SON.

Unlike the case of West Africa rainfall and Atlantic Ocean SSTA, the outlook for East Africa predictability is more promising. The strong influence of the tropical Pacific variability, which is largely predictable, especially once the evolution of an ENSO event has begun (Landsea and Knaff, 2000; Landman and Mason 2001), and the relatively slow time scale of that evolution, implies that predictions for the Indian Ocean can improve upon persistence. Even the simplest of predictions of Indian Ocean SSTA for SON based on tropical Pacific temperatures improves upon persistence over most of the Indian Ocean. Root mean squared errors are smaller over most of the Indian Ocean basin for predictions of SON SSTA by using a simple linear regression model with August NINO3.4 anomalies as the only predictor compared to using persistence of August SSTA (not shown). Using more sophisticated models to predict Indian Ocean sea temperature anomalies, further improvements are likely to be achieved, and it seems reasonable to expect these improvements to result in more accurate forecasts of SON precipitation of eastern Africa.

\section{Discussion and summary}

Sea surface temperature anomalies (SSTA), especially in the tropics, typically vary slowly enough that a prediction of persistence is difficult to beat at lead times out to 3 or 4 months. However, when atmospheric general circulation models (AGCMs) are used to predict seasonal climate, errors in the predicted SSTs can translate into significant losses in predictive skill. By comparing long historical runs of an AGCM 
forced with both observed SSTs and persisted SSTA, the errors introduced by imperfect boundary conditions are revealed.

Operational skill levels of AGCMs must include the uncertainty inherent in the SST predictions. Under persisted SSTA forcing the ECHAM3.6 AGCM retains much of the precipitation skill seen under simulation forcing. However, several regions that exhibit good simulation skill are poorly predicted in an operational setting using persisted SSTA. Even over regions for which true prediction skill remains significant, the magnitude of the skill measure is often reduced implying that skill levels will be overestimated if based only on simulation runs.

Systematic biases in a model's response to predicted SSTs must also be quantified. Biases introduced by the particular SST forecast strategy are likely to be translated into biases in the ensemble distribution. Such biases directly affect the interpretation of the strength of a seasonal climate anomaly and its associated uncertainty by altering the mean seasonal signal and/or noise characteristics. Although signal-to-noise ratios are often used to indicate potential predictability in a model, regional changes in signal-to-noise do not appear responsible for the loss of skill in the ECHAM3.6 runs. Rather, relative to the simulations, the persisted SSTA runs typically yield a stronger signal-to-noise ratio for precipitation in regions where correlation skill is weaker. The change in signal-to-noise characteristics results primarily from an increase in the local precipitation signal with little change in the regional noise levels. If not properly accounted for, such a bias would lead a forecaster to suggest that the magnitude of a seasonal rainfall anomaly will be much stronger than is actually being indicated. The enhancement of signal, particularly in the tropics, may be related to the fixed pattern of SSTA forcing the AGCM for the 3month season in places where the observed SSTA is more variable from month to month. Such a hypothesis would require regional precipitation to respond nonlinearly to local SSTA. Preliminary analysis suggests this is possible, but it is not conclusive, requiring further experimentation. The enhancement of signal may also be due to important changes in the magnitude of local SSTA variance, such as that due to the seasonal evolution of SSTA variance patterns.

The systematic error biases apparent between the simulation and persisted hindcast runs and the SST-related causes for those biases were examined through two 
case studies. In West Africa during the JJA rainy season, errors in the SST anomalies over the tropical Atlantic contribute most significantly to loss of skill over the region. The structure of the SSTA error is well defined with a maximum of one sign along the equatorial Atlantic and a maximum of opposite sign off the western coast of West Africa, from Mauritania to Liberia. This error pattern in SSTA results in an erroneous meridional shift of the ITCZ analogous to the relationship between interannual tropical Atlantic SST variability and West Africa rainfall variability that has been well documented. However, the evolution of SSTA in the tropical Atlantic from May to August is noisy, and may not be easily predictable. The SSTA error in the tropical Atlantic during JJA does bear some resemblance to the seasonal evolution of SSTA variance. Regions where locally high variance dies off rapidly during the forecast season could be preferentially damped. Still important variability is developing in the equatorial Atlantic during the JJA season, a situation that even modified persistence cannot handle. At this time statistical and dynamical predictions of equatorial and south Atlantic SSTA cannot beat persistence, thus the potential to predict JJA (or JAS) rainfall over West Africa using SST information prior to June remains low.

The second case study focussed on East Africa during the SON rainy season. Here, errors in the Indian Ocean SSTA are responsible for loss of skill in the persisted hindcasts. These errors are largely due to the influence of the tropical Pacific on SSTA variability in the Indian Ocean. Since ENSO events undergo rapid growth during the middle of the year, and their impact on the Indian Ocean is seen approximately three months later, SON represents a season of potentially rapidly changing SSTA in the Indian Ocean. Persisting August SSTA misses this evolution in the Indian Ocean leading to substantial discrepancies in the rainfall anomalies over East Africa. The strong relationship between the Indian Ocean and the Pacific Ocean suggests that predictions of SSTA for the Indian Ocean can improve upon persistence.

As illustrated in these case studies, identifying in what way the imperfect SST predictions are biasing the model response, such as the sign, magnitude, and/or intraensemble variance, and in what regions the imperfect SST predictions are most influential are important steps towards improving SST predictions and associated climate predictions. 


\section{References}

Anderson JL, Stern WF (1996) Evaluating the potential predictive utility of ensemble forecasts. J Climate 9: $260 ? 269$

Barnett TP (1995) Monte Carlo climate forecasting. J Climate 8: 1005 ? 1022

Barnston AG, van den Dool HM, Zebiak SE, Barnett TP, Ji M, Rodenhuis DR, Cane MA, Leetmaa A, Graham NE, Ropelewski CF, Kousky VE, O'Lenic EA, Livezey RE (1994) Long-lead seasonal forecasts ? where do we stand? Bull Amer Meteorol Soc 75: 2097? 2114

Barnston AG, Glantz MH, He Y (1999a) Predictive skill of statistical and dynamical climate models in forecasts of SST during the 1997?98 El Niño episode and the 1998 La Niña onset. J Climate, 80, 217? 244

Barnston AG, Leetmaa A, Kousky VE, O’Lenic EA, Wagner AJ, Le Comte DM, Kumar A, Tinker R, Churchill RH (1999b) NCEP forecasts for the El Niño of $1997 ? 98$ and its U. S. impacts. Bull. Amer. Meteorol. Soc., 80, $1829 ? 1852$

Beltrando G (1990) Space-time variability of rainfall in April? November over East Africa during the period 1932? 1983. Int J Climatol, 10, 691?702

Bengtsson L, Schlese U, Roeckner E, Latif M, Barnett TP, Graham NE (1993) A two tiered approach to longrange climate forecasting. Science 261: 1026? 1029

Brankovic C, Palmer TN, (1997) Atmospheric seasonal predictability and estimates of ensemble size. Mon Weather Rev 125: 859? 874

Brankovic C, Palmer TN, (2000) Seasonal skill and predictability of ECMWF PROVOST ensembles. Q J R Meteorol Soc 126: 2035?2068

Brankovic C, Molteni F, Tibaldi S, Cubasch U (1990) Extended-range predictions with the ECMWF models: time-lagged ensemble forecasting. Q J R Meteorol Soc 116: 867?912

Brankovic C, Palmer TN, Ferranti L (1994) Predictability of seasonal atmosperhic variations. J Climate 7: $217 ? 237$

Chervin RM (1986) Interannual variability and seasonal climate variability. J Atmos Sci 43: 233? 251

Deutches Klimarechenzentrum (DKRZ) (1992) The ECHAM3 atmospheric general circulation model. Tech Report 6, Hamburg, Germany, 184pp

Feddersen H, Navarra A, Ward MN (1999) Reduction of model systematic error by statistical correction for dynamical seasonal predictions. J Climate 12: 1974? 1989

Ferranti L, Molteni F, Brankovic C, Palmer TN (1994) Diagnosis of extratropical variability in seasonal integrations of the ECMWF model. J Climate 7: 849? 868

Goddard L, Graham NE (1999) The importance of the Indian Ocean for simulating rainfall anomalies over eastern and southern Africa. J Geophys Res 104: 19099? 19116

Goddard L, Mason SJ, Zebiak SE, Ropelewski CF, Basher R, Cane MA (2001) Current approaches to seasonal to interannual climate predictions. Int J Climatol 21: 1111? 1152

Kumar A, Hoerling MP (1995) Prospects and limitations of seasonal atmospheric GCM predictions. Bull Amer Meteorol Soc 76: 335?345

Kumar A, Barnston AG, Hoerling MP (2001) Seasonal predictions, probabilistic verifications, and ensemble size. J Climate 14: 1671? 1676 
Landman WA, Mason SJ (2001) Forecasts of near-global sea surface temperatures using canonical correlation analysis. J Climate 14: 3819 ? 3833

Landsea CW, Knaff JA (2000) How much "skill” was there in forecasting the very strong 1997?98 El Niño? Bull Amer Meteorol Soc 81: 2107?2120

Latif M, Barnett TP, Cane MA, Flügel M, Graham NE, von Storch H, Xu JS, Zebiak SE (1994) A review of ENSO prediction studies. Clim Dyn 9: 167? 179

Latif M, Anderson DLT, Barnett TP, Cane MA, Kleeman R, Leetmaa A, O'Brien J, Rosati A, Schneider E (1998) A review of the predictability and prediction of ENSO. J Geophys Res 103: 14375? 14393

Lamb PJ (1978a) Case studies of tropical Atlantic surface circulation patterns during recent sub-Saharan weather anomalies: 1967 and 1968. Mon Wea Rev 106: 483 ? 491

Lamb PJ (1978b) Large-scale tropical Atlantic surface circulation patterns associated with sub-Saharan weather anomalies. Tellus A30: 240?251

Lau N-C (1985) Modeling the seasonal dependence of the atmospheric response to observed El Niøs in $1962 ? 76$. Mon Wea Rev 113: 1970? 1996

Lough JM (1986) Tropical Atlantic sea surface temperatures and rainfall variations in Subsaharan Africa. Mon Wea Rev 114: $561 ? 570$

Madden RA (1976) Estimates of natural variability of time-averaged sea level pressure. Mon Wea Rev 104: $942 ? 952$

Mason SJ, Mimmack GM (2002) A comparison of some methods of probabilistic forecasting of ENSO, J Climate 15: $8 ? 29$

Mason SJ, Goddard L (2001) Probabilistic precipitation anomalies associated with ENSO. Bull Amer Meteorol Soc. 82: $619 ? 638$

Mason SJ, Goddard L, Graham NE, Yulaeva E, Sun L, Arkin PA (1999) The IRI seasonal climate prediction system and the 1997/98 El Niño event. Bull Amer Meteorol Soc 80: 1853? 1873

Mo KC, Wang XL (1995) Sensitivity of the systematic error of extended range forecasts to sea surface temperature anomalies. J Climate 8: 1533 ? 1543

Mutai CC, Ward MN (2000) East African rainfall and tropical circulation/convection on intraseasonal to interannual timescales. J Climate 13: 3915 ?3939

Neelin JD, Battisti DS, Hirst AC, Jin FF, Wakata Y, Yamagata T, Zebiak SE (1998) ENSO theory. J Geophys Res 103: $14261 ? 14290$

New M, Hulme M, Jones P (1999) Representing twentieth-century space-time climate variability. Part I: Development of 1961?90 mean monthly terrestrial climatology. J Climate 12: 829? 856

New M, Hulme M, Jones P (2000) Representing twentieth-century space-time climate variability. Part II: Development of 1901?96 monthly grids of terrestrial surface climate. J Climate 13: 2217?2238

Nicholson SE and Kim J (1997) The relationship of the El Nino? Southern Oscillation to African rainfall. Int J Climatol, 17: 117? 135

Ogallo LJ (1988) Relationship between seasonal rainfall in East Africa and Southern Oscillation. Int J Climatol, 8: 34 ? 43

Palmer TN, Anderson DLT (1994) The prospects for seasonal forecasting ? a review paper. Q J R Meteorol Soc 117: $91 ? 106$ 
Peng PT, Kumar A, Barnston AG, Goddard L (2000) Simulation skills of the SST-forced global climate variability of the NCEP-MRF9 and the Scripps MPI ECHAM3 models. J Climate 13: 3657 ?679

Penland C, Matravosa L (1998) Prediction of tropical Atlantic sea surface temperatures using linear inverse modeling. J Climate 11: 483? 496

Repelli CA, Nobre P (2001) Statistical prediction of sea surface temperature over the tropical Atlantic. Int J Climatol, (in press)

Reynolds RW, Smith TM (1994) Improved global sea surface temperature analysis using optimum interpolation. J Climate 7: $929 ? 948$

Ropelewski CF, Halpert MS (1987) Global and regional scale precipitation patterns associated with El Nino/Southern Oscillation. Mon Wea Rev, 115: 1606? 1626

Rowell DP (1998) Assessing potential predictability with an ensemble of multidecadal GCM simulations. J Climate 11: 109? 120

Shea DJ, Madden RA (1990) Potential for long-range prediction of monthly mean surface temperatures of North America. J Climate 3: 1444? 1451

Smith TM, Reynolds RW, Livezey RE, Stokes DC (1996) Reconstruction of historical sea surface temperatures using empirical orthogonal functions. J Climate 9: 1403? 1420

Stockdale TN, Busalacchi AJ, Harrison DE, Seager R (1998) Ocean modeling for ENSO. J Geophys Res 103 : $14325 ? 14355$

Ward MN (1998) Diagnosis and short-lead time prediction of summer rainfall in tropical North Africa at interannual and multidecadal timescales. J Climate 11: 3167?3191

Ward MN, Navarra A (1997) Pattern analysis of SST-forced variability in ensemble GCM simulations: examples over Europe and the tropical Pacific. J Climate 10: 2210?2220

Zwiers FW (1996) Interannual variability and predictability in an ensemble of AMIP climate simulations conducted with the CCC GCM2. Clim Dyn 12: 825? 848 